\title{
Aferindo a capacidade de influência das conferências de políticas públicas sobre os programas das respectivas políticas setoriais
}

Viviane Petinelli

\section{Introdução ${ }^{1}$}

O Brasil contemporâneo não apenas dispõe de diversas arenas participativas, como também estas integram o processo de um amplo e diversificado conjunto de políticas públicas. Esses espaços proporcionam tanto interfaces de participação individuais, como ocorre nos casos das ouvidorias, quanto interfaces coletivas, como são os casos das audiências públicas, do Orçamento Participativo (OP) e do Plano Diretor Municipal (PDM) no nível local e dos conselhos gestores e das conferências de políticas públicas nas três esferas da Federação.

A emergência e a incorporação dessas experiências democráticas ao processo de políticas tiveram início no final da década de 1980, impulsionadas pela Constituição Democrática de 1988 (doravante CF/88) e pelos governos democráticos que se seguiram a ela. Por meio do discurso neoliberal de superação do modelo intervencionista de Estado, de um lado, e de projetos democrático-participativos, de outro, novas relações políticas e institucionais entre atores estatais e não estatais surgiram e novos canais e instituições participativas foram criados no âmbito de diversas políticas setoriais.

O compartilhamento e a transferência de competências do governo central para os subnacionais e para o mercado e a sociedade civil, somados à proliferação de interfaces de participação social, trouxeram implicações para o processo de políticas. Essas iniciativas alargaram o leque de atores envolvidos direta e indiretamente nesse processo, o que, por sua vez, tornou-o, em alguma medida, mais plural e, por conseguinte, mais democrático e inclusivo. Por outro lado, a ampliação da participação em densidade e diversidade tornou o processo de políticas mais disputado e mais conflitivo em diversas áreas, aumentando, consequentemente, os custos de coordenação e de tomada de decisão para os atores estatais.

\footnotetext{
${ }^{1}$ Este artigo trata da primeira parte da tese entitulada "Uma análise dos condicionantes da capacidade de influência das conferências de políticas públicas sobre os programas das respectivas políticas setoriais: o caso da $1^{\text {a }}$ CAP, $1^{\text {a }}$ Concidades, $1^{\text {a }}$ CMA, $1^{\text {a }} \mathrm{CE}, 1^{\text {a }}$ CPM e $1^{\text {a }}$ CPIR", defendida e aprovada no dia 6 de junho de 2014, junto ao Programa de Pós-Graduação em Ciência Política da Universidade Federal de Minas Gerais.
} 
Tal reconfiguração do processo de políticas públicas trouxe novos desafios teóricos e empíricos para as investigações acerca da formação e das mudanças nas políticas. Em um contexto mais descentralizado, participativo e plural, estas resultariam de interesses e ideias de atores políticos, burocratas, grupos de interesse econômico, experts e mídia, negociados e discursivamente apresentados em arenas diversas de interlocução e tomada de decisão, sob regras e procedimentos institucionais e contextos políticos e socioeconômicos distintos. No processo de políticas públicas, portanto, interesses e/ou ideias dos atores individuais e coletivos consistiriam fontes das políticas, os quais, apresentados em espaços de discussão e tomada de decisão, seriam constrangidos pelo conjunto de regras e procedimentos destes - desenho institucional - e pela dinâmica política entre os grupos de atores estatais e não estatais neles presentes. Dessa forma, análises a respeito das políticas públicas deveriam levar em consideração todos esses aspectos, controlados ou variando, para apontar e explicar seus resultados e a efetividade deles.

No âmbito do Executivo federal brasileiro, essa configuração mais democrática do processo de políticas resulta, dentre outros fatores, da realização de conferências de políticas públicas a respeito de um extenso e variado conjunto de políticas setoriais. Convocadas por ato normativo do presidente da República, de ministros ou de conselhos gestores, essas instituições participativas têm sido realizadas, notadamente, para agendar novas questões públicas, propor novas ações e avaliar propostas governamentais a ser implementadas e/ou em execução no momento do encontro (Souza, 2012). Discutidas e apreciadas por um amplo e diversificado leque de atores estatais e não estatais em múltiplos encontros sequenciais nos níveis subnacional e nacional, essas propostas têm sido encaminhadas para as instituições competentes a fim de ser incorporadas nas respectivas políticas.

As conferências, portanto, têm constituído um espaço de discussão de velhas e novas políticas governamentais e integrado um processo decisório mais amplo - o de formação da agenda - que envolve múltiplos e variados atores e instituições hierarquicamente ordenadas e interdependentes entre si. Como corolário, os resultados dessas arenas participativas, e, portanto, a efetividade delas, estão condicionados a aspectos político-institucionais decorrentes do processo de políticas públicas, quais sejam, arcabouço institucional legal e dinâmica política da política pública que elas debatem, além de ser impactados por fatores diretamente associados ao processo conferencial, como o desenho institucional que as conferências assumem.

Tal complexidade de avaliação da efetividade das conferências no que se refere a impacto sobre as políticas públicas justifica, em certa medida, as poucas contribuições da literatura nacional (e internacional) sobre o tema. De modo geral, quando tratam de efetividade, as investigações interpretam-na enquanto qualidade deliberativa e nível de inclusão política e de pluralidade participativa, a partir da análise do desenho institucional desses espaços (Pires, 2011). 
As exceções a esse respeito constituem as análises de Pogrebinschi (2013), Pogrebinschi e Santos (2011), Avritzer (2013) e Petinelli (2011, 2013). Os primeiros mostram que parcela das propostas aprovadas nessas arenas tem subsidiado os decretos presidenciais e os projetos de lei elaborados por deputados federais e senadores desde a redemocratização do país, enquanto os segundos apontam evidências de que uma quantidade média de recomendações tem sido traduzida em ações pelo governo após a realização das conferências. Não obstante, ainda se carece de um modelo que mensure e explique os efeitos das recomendações aprovadas nas conferências sobre os programas das respectivas políticas.

Este artigo se coloca como uma tentativa de preencher a primeira lacuna, propondo um método para aferir a capacidade de influência de conferências sobre as respectivas políticas setoriais pela comparação entre o conteúdo das propostas nelas aprovadas e o conteúdo dos programas elaborados após o processo conferencial. Por capacidade de influência, entende-se o grau de incorporação das propostas aprovadas nos programas das respectivas políticas.

A capacidade de influência das conferências foi observada para uma amostra de seis conferências inéditas, selecionadas a partir de três critérios: coalizão governativa no poder, vontade/disposição política e caráter e edição da conferência. Cada coalizão e ator político apresentam um conjunto de preferências e prioridades políticas que moldam a agenda de políticas públicas. Para controlar os efeitos dessas variáveis sobre a capacidade de influência das conferências, escolheram-se somente conferências realizadas pelo governo Lula, convocadas por decreto presidencial e organizadas por ministérios liderados por atores políticos, membros do PT ou de partidos de esquerda, cuja participação consiste em importante bandeira política.

Além disso, tomou-se o cuidado de manter constante o caráter e a edição da conferência, de modo a controlar os efeitos da previsão legal e do aprendizado, respectivamente, sobre a capacidade de influência das conferências de políticas examinadas. Em decorrência, foram selecionados apenas processos consultivos, realizados pela primeira vez na respectiva área de política pública.

Da aplicação desses critérios, chegou-se às seguintes conferências: a $1^{a}$ Conferência de Aquicultura e Pesca (doravante $1^{\text {a }}$ CAP), a $1^{\text {a }}$ Conferência de Cidades (1 ${ }^{a}$ Concidades), a $1^{\text {a }}$ Conferência de Meio Ambiente (doravante $1^{\text {a }}$ CMA), a $1^{\text {a }}$ Conferência de Esporte ( $\left.1^{\mathrm{a}} \mathrm{CE}\right)$, a $1^{\text {a }}$ Conferência de Políticas para Mulheres (doravante $1^{\mathrm{a}} \mathrm{CPM}$ ) e a $1^{\text {a }}$ Conferência de Políticas de Promoção de Igualdade Racial (1 ${ }^{a}$ CPIR). O debate e o processo decisório nesses seis encontros foram baseados em um caderno de sugestões, elaborado pelo ministério ou secretaria especial competente, o qual continha propostas gerais para a respectiva política setorial.

Posto isso, as recomendações finais de cada conferência examinada foram classificadas em propostas sugeridas, quando encaminhadas junto ao caderno-base, ou inéditas, quando elaboradas ao longo do processo conferencial. A capacidade de 
influência de cada tipo de proposta foi aferida separadamente e, da comparação entre elas, foi mensurada a capacidade real de influência das conferências, dada pela proporção de recomendações inéditas incluídas sobre o total incorporado.

Dos processos conferenciais cuja porcentagem de recomendações inéditas incorporadas pelo governo em relação ao total de recomendações incluídas foi superior a $70 \%$, resultaram políticas com forte cunho societário ${ }^{2}$, enquanto das conferências cuja porcentagem de recomendações inéditas incluídas foi inferior a $30 \%$ do total de propostas aprovadas derivaram ações com forte lastro governamental. As políticas resultantes de uma quantidade percentual equilibrada de propostas inéditas e sugeridas (31\%-70\%) foram consideradas partilhadas, de cunho governamental e societário.

Este artigo está organizado em três seções, para além desta Introdução e das Considerações Finais. Na primeira, "Desenho institucional da $1^{a}$ CAP, $1^{\text {a }}$ Concidades, $1^{a}$ CMA, $1^{\text {a }} \mathrm{CE}, 1^{\text {a }}$ CPM e $1^{\text {a }}$ CPIR", descreve-se o desenho institucional dos seis processos conferenciais aqui examinados, quais sejam, $1^{\text {a } C A P}, 1^{\text {a }}$ Concidades, $1^{\mathrm{a}} \mathrm{CMA}, 1^{\mathrm{a}} \mathrm{CE}, 1^{\mathrm{a}}$ CPM e $1^{\text {a }}$ CPIR, no que se refere às etapas e aos espaços de participação e ao método de seleção e à composição de participantes destes. Em seguida, em "Metodologia de análise da capacidade de influência de conferências sobre as respectivas políticas setoriais", apresenta-se o método proposto para aferir a capacidade de influência das conferências sobre os programas das respectivas políticas setoriais. Na última seção, "Aferindo a

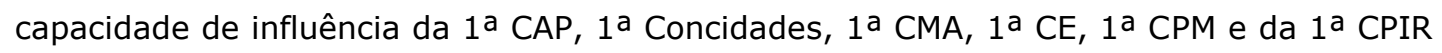
sobre as respectivas políticas setoriais", mensuram-se e examinam-se os resultados obtidos para a capacidade total e real de influência das $1^{\text {a } C A P}, 1^{\text {a }}$ Concidades, $1^{\text {a }}$ CMA, $1^{\text {a }}$ CE, $1^{\text {a }}$ CPM e $1^{\text {a }}$ CPIR e se apontam os efeitos destas em termos de conteúdo das políticas públicas.

\section{Desenho institucional da 1 a CAP,}

\section{$1^{\text {a }}$ Concidades, $1^{\text {a }}$ CMA, $1^{\text {a }}$ CE, $1^{\text {a }}$ CPM e $1^{\text {a }}$ CPIR}

Embora as conferências não constituam arranjos participativos recentes no Brasil, somente na última década elas se tornaram importantes espaços de interlocução e tomada de decisão conjunta entre governo e sociedade civil em grande parcela das políticas setoriais no nível nacional. Dentre as políticas que passaram a ser debatidas em conferências, estão a de aquicultura e pesca, a urbana, a de meio ambiente, a de

\footnotetext{
2 Vale ressaltar aqui que a adoção do termo "societário" para distinguir as propostas advindas do próprio processo conferencial das sugestões encaminhadas pelos setores do governo federal não busca desconsiderar nem mostrar desconhecimento quanto à heterogeneidade dos atores que as propõem. Sabese que estas decorrem de uma diversidade de grupos não só da sociedade civil como também estatais. No entanto, a aprovação destas exige parecer positivo da maioria dos delegados participantes e, em todos os processos conferenciais analisados, a maioria dos delegados representava a sociedade civil. Daí denominálas propostas com forte cunho societário: mesmo não tendo sido sugeridas por atores societais, elas foram aprovadas por estes.
} 
esporte, as políticas para mulheres e de promoção da igualdade racial. Para todas elas, o primeiro processo de conferências foi realizado no primeiro mandato do ex-presidente Lula (2003-2006) e já foi seguido por, pelo menos, outras duas conferências ${ }^{3}$ (Brasil, 2013a). Ademais, todas elas apresentaram o objetivo de propor diretrizes para a

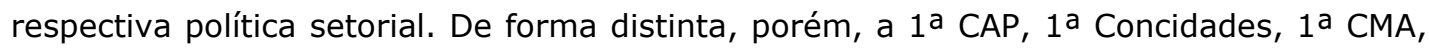
$1^{\text {a }} \mathrm{CE}, 1^{\text {a }} \mathrm{CPM}$ e a $1^{\text {a }}$ CPIR assumiram desenhos institucionais particulares, conforme mostrado a seguir.

\section{$1^{a}$ Conferência de Aquicultura e Pesca}

A $1^{\text {a }}$ CAP aconteceu no período de junho a novembro de 2003. Nos meses de junho a outubro, foram realizados 27 encontros nos estados e no Distrito Federal e, de 25 a 27 de novembro de 2003, ocorreu a etapa nacional. As conferências estaduais e a nacional foram organizadas por um Grupo de Trabalho, composto por membros da Secretaria Especial de Aquicultura e Pesca (doravante Seap) e das principais organizações da sociedade civil vinculadas a essa política setorial. Todos esses encontros tiveram como objetivo discutir e propor diretrizes para o Plano Estratégico de Desenvolvimento Sustentável da Aquicultura e da Pesca a ser implementado pela Seap no primeiro mandato de Lula (2003-2006) (Brasil, 2003a, 2003b, 2003c).

Esse plano serviu como texto-base de discussão na $1^{\text {a }}$ CAP. Ele foi elaborado pela Seap e foi composto por 94 propostas relativas às estratégias e metas para a Política de Aquicultura e Pesca, e a oito eixos temáticos, a saber: (1) Participação; (2) Sustentabilidade das atividades de aquicultura e pesca; (3) Estruturação do setor de aquicultura; (4) Estruturação da pesca oceânica, continental e costeira; (5) Políticas sociais para o setor da aquicultura e pesca; (6) Políticas de crédito; (7) Política de desenvolvimento tecnológico; e (8) Produção e Fome Zero (Brasil, 2003c). Essas propostas foram discutidas por 5.280 representantes estatais e não estatais ao longo do processo conferencial. Os representantes do Poder Executivo e do Legislativo municipal, estadual e federal e do Ministério Público foram indicados pelas respectivas autoridades institucionais, ao passo que os representantes societais foram eleitos, inicialmente, em assembleias de base, realizadas por sindicatos, movimentos e associações de pescadores artesanais e de empresários da pesca e da aquicultura, por entidades estaduais de defesa do consumidor e instituições de pesquisa e entidades não governamentais estaduais com atuação no setor e, nos encontros estaduais, na plenária final entre seus pares. No total, foram eleitos 953 delegados e delegadas para participar da conferência nacional.

\footnotetext{
${ }^{3}$ As outras conferências de aquicultura e pesca foram realizadas em 2006 e 2009, as de cidades, em 2005, 2007, 2010, 2012, os encontros de esporte foram organizados em 2006, 2009 e 2013, as conferências sobre meio ambiente em 2005, 2008 e 2013, os encontros sobre políticas para mulheres foram realizados em 2007 e 2012 e as conferências de promoção da igualdade racial, em 2009 e 2013 (Brasil, 2013a).
} 
Nessa etapa, a participação dos delegados e dos convidados se deu em cinco momentos: na plenária inicial, em plenárias regionais, em Grupos de Trabalho (GTs), em plenárias temáticas e na plenária final. Do extenso debate e processo decisório desenrolados nesses espaços, resultaram 175 propostas relacionadas aos pressupostos e estratégias do projeto político e à participação social nessa política, à estruturação e desenvolvimento do setor de aquicultura e pesca, e a políticas sociais para os trabalhadores desses setores. Esse leque de recomendações foi reunido para compor o Plano Estratégico de Desenvolvimento Sustentável da Aquicultura e da Pesca, a ser encaminhado ao presidente da República (Brasil, 2004a).

\section{$1^{a}$ Conferência de Cidades}

A $1^{\text {a }}$ Concidades aconteceu entre os meses de julho e outubro de 2003 nos níveis local, estadual e nacional. Os encontros municipais ou regionais foram realizados do início de julho até 15 de agosto e foram seguidos pela etapa estadual, cuja data-limite de realização foi 28 de setembro. Um mês depois, de 23 a 26 de outubro, aconteceu a conferência nacional. No total, foram 1.430 conferências municipais, 150 encontros regionais, 26 conferências estaduais e uma no Distrito Federal. Todos esses encontros foram organizados por uma Comissão Preparatória e por uma Coordenação Executiva, compostas por representantes governamentais e por representantes das diversas organizações da sociedade civil. Em todos eles, ademais, os objetivos foram o de propor princípios e diretrizes para a construção de uma política democrática e integrada para as cidades e o de avaliar os programas em andamento e as legislações vigentes a esse respeito (Brasil, 2003e).

O debate e o processo decisório nas 1.580 conferências locais e 27 conferências estaduais foram referenciados por um caderno-base, elaborado por uma equipe técnica do Ministério das Cidades (doravante MCidades). Este foi composto por 100 sugestões de propostas para três grandes eixos temáticos: "Gestão Democrática e Conselho das Cidades", "Princípios e Diretrizes da Política Nacional de Desenvolvimento Urbano" e "Ações e Prioridades para uma Política Nacional de Desenvolvimento Urbano" (Brasil, 2003f, 2003g). Essas propostas foram discutidas por dezenas de milhares de cidadãos e cidadãs, selecionados, por meio de eleição e indicação - exclusivamente para os representantes estatais - para participar das etapas estaduais e nacional. Nesta última, 2.510 delegados e delegadas participaram por meio de mesas de debates, grupos de trabalho (GTs) e plenárias.

Da discussão e tomada de decisão destes, resultaram 298 recomendações, relativas à organicidade do conselho nacional, aos princípios e diretrizes do PNDU e às ações e prioridades dessa política (Brasil, 2003e). Esse conjunto de propostas foi reunido em um único documento e encaminhado para o presidente da República e o MCidades para servir como "referências balizadoras e orientadoras das ações do mesmo e das 
formulações das políticas setoriais bem como da primeira proposta da Política Nacional de Desenvolvimento Urbano" (Brasil, 2004b, p. 9).

\section{$1^{a}$ Conferência de Meio Ambiente}

A $1^{\text {a }}$ CMA foi realizada de setembro a novembro de 2003. De 15 de setembro a 5 de novembro, aconteceram 27 pré-conferências nacionais nos estados e no Distrito Federal, as quais foram seguidas pelo encontro nacional entre 28 e 30 de novembro. Todos os encontros foram organizados por uma Comissão Organizadora, formada por representantes governamentais e de diversas organizações da sociedade civil, e tiveram como objetivo propor diretrizes para o fortalecimento do Sistema Nacional de Meio Ambiente (doravante Sisnama) (Brasil, 2003h, 2003i).

As diretrizes básicas do Sisnama compuseram o caderno-base de discussão da $1^{a}$ CMA. Esse caderno foi elaborado por uma equipe técnica do Ministério do Meio Ambiente (MMA) e composto por 109 propostas sugeridas relativas a seis eixos temáticos. Foram discutidos o Sisnama, a política de recursos hídricos, a de biodiversidade, a política de agricultura, pecuária, recursos pesqueiros e silvicultura, o meio ambiente urbano e a infraestrutura, e as mudanças climáticas (Brasil, 2003j).

Esse conjunto de diretrizes foi debatido por atores estatais e societais diversos, os quais participaram livremente nos encontros estaduais e foram eleitos como representantes nessa etapa para o encontro nacional. Em ambas as etapas, a participação desses atores aconteceu em três momentos subsequentes: a plenária de abertura, os GTs e a plenária final. Nesses espaços, esses atores aprovaram 644 propostas relativas aos seis eixos temáticos propostos (Brasil, 2003i). Todas as diretrizes aprovadas foram encaminhadas ao Ministério do Meio Ambiente (MMA) para servir como base do Plano de Ação 2004-2007.

\section{$1{ }^{a}$ Conferência de Esporte}

A $1^{\text {a }}$ CE aconteceu no período entre março e junho de 2004. Em março e abril, foram realizadas 60 conferências municipais e 116 encontros regionais, envolvendo 873 municípios brasileiros. Esses encontros foram seguidos por 26 conferências estaduais e 1 no Distrito Federal, organizadas em abril e maio. A etapa nacional aconteceu entre 17 e 20 de junho de 2004. Todos os encontros foram organizados por uma comissão, composta por representantes governamentais e do Poder Legislativo, de entidades nacionais de administração do esporte, tais como o Comitê Olímpico Brasileiro e a Confederação Brasileira de Futebol, e por representantes de organizações da sociedade civil, dentre elas, sindicatos, conselhos de educação física, entidades estudantis e movimentos sociais. 
A $1^{\text {a }}$ CE teve como objetivo democratizar e propor diretrizes para a política nacional de esporte e lazer. Nesse sentido, o Ministério do Esporte (ME) elaborou um texto-base, composto por 119 propostas a respeito de oito temas distintos (Brasil, 2004d). Os temas tratados compreendiam os princípios, diretrizes e objetivos da política nacional de esporte, suas três dimensões: esporte de alto rendimento, esporte como lazer e esporte educacional, e aspectos legais e estruturais dessas três modalidades (Brasil, 2004f).

Esse caderno-base foi debatido por cerca de 83 mil pessoas, dentre as quais, 861 foram eleitas a partir de consenso, de votação nominal ou de votação por chapa como representantes governamentais e sociais no encontro nacional. Nessa última etapa, delegados e delegadas participaram de plenárias (inicial e final), de mesas de debates e grupos de trabalho. Da discussão e tomada de decisão nesses espaços, derivaram 103 propostas, sendo que 35 delas propunham a criação do Sistema Nacional de Esporte e Lazer e, nesse sentido, tratavam dos princípios, diretrizes e objetivos desse sistema. Esse leque de propostas foi encaminhado ao Ministério do Esporte (ME) para balizar a formulação dos programas e ações desse ministério para os anos seguintes.

\section{1 a Conferência de Políticas para Mulheres}

A $1^{\text {a }}$ CPM foi realizada entre março e julho de 2004 nos níveis local, estadual e nacional. No total, foram mais de 2 mil conferências municipais e 27 encontros estaduais realizados previamente à conferência nacional, entre 15 e 17 de julho. Esses encontros foram organizados por uma comissão, composta paritariamente por membros do conselho de políticas para mulheres e por representantes da Secretaria de Políticas para Mulheres de cada nível da Federação. Todos esses encontros tiveram como objetivo elaborar um Plano Nacional de Políticas para as Mulheres (I PNPM) e avaliar as políticas desenvolvidas, até aquele momento, pela Secretaria de Políticas para Mulheres (Brasil, 2004g).

O processo de discussão e tomada de decisão nos mais de 2 mil encontros da $1^{a}$ CPM se deu com base no documento: "Propostas de Diretrizes para uma Política Nacional para as Mulheres - PNM", formulado pela Secretaria de Políticas para Mulheres (doravante SPM) em parceria com o Conselho Nacional de Direitos da Mulher (Brasil, 2004h). Esse texto-base foi composto por 41 recomendações, divididas em uma parte introdutória e em cinco eixos temáticos. Foram eles: enfrentamento da pobreza, políticas de promoção do bem-estar e qualidade de vida para as mulheres, educação, cultura, comunicação e produção do conhecimento para a igualdade de gênero, direitos humanos das mulheres e segurança contra violência à mulher. Nenhuma sugestão relativa a natureza, princípios e diretrizes da Política Nacional (parte introdutória) foi encaminhada pela SPM para apreciação na $1^{\text {a }}$ CPM (Brasil, 2004g). 
Esse conjunto de sugestões foi discutido por cerca de 120 mil atores políticos e sociais, dos quais 1.787 foram eleitos como representantes para participar da conferência nacional. Nessa e nas demais etapas, esses atores participaram de plenárias, painéis temáticos e GTs, tal como observado na $1^{\text {a }}$ CE. Dos debates nesses espaços, foram aprovadas 137 recomendações quanto a natureza, princípios e diretrizes da política nacional, de políticas sociais e dos direitos humanos das mulheres (Brasil, 2004g). Essas propostas foram sistematizadas em um único documento para servir como subsídio para o I PNPM.

\section{$1^{a}$ Conferência de Políticas de Promoção da Igualdade Racial}

A $1^{\text {a }}$ CPIR aconteceu no primeiro semestre de 2005 com o propósito de construir o Plano Nacional de Políticas de Promoção da Igualdade Racial (Planappir). O Planappir foi discutido em 1.332 encontros municipais, abertos a toda a população, em 26 conferências estaduais e 1 no Distrito Federal e na conferência nacional, realizada de 30 de junho a 2 de julho de 2005, a partir de um caderno-base, elaborado por uma comissão, composta por representantes governamentais e de organizações da sociedade civil (Brasil, 2005c). Esse caderno foi composto por 73 sugestões sobre 12 temas distintos. Parte das propostas tratava de políticas de trabalho e desenvolvimento econômico, de educação, de saúde e de políticas sobre diversidade cultural. Outras diziam respeito a direitos humanos, segurança pública e a ações específicas para comunidades remanescentes de quilombos, população indígena, juventude negra e mulher negra. As demais se referiam a aspectos políticos, religiosos e institucionais dessa política (Brasil, 2005c).

Esse leque de propostas foi discutido por aproximadamente 92.750 cidadãos e cidadãs, dos quais 2.643 foram eleitos nos encontros estaduais para participar na etapa nacional. Nesse último encontro, os atores participaram de seis momentos subsequentes: plenária de abertura, palestras, painel de diálogo, painéis simultâneos, GTs e plenária final. Neles, as diretrizes sugeridas pela comissão organizadora foram debatidas e novas propostas emergiram e foram apreciadas. Desse processo, 1.055 recomendações foram aprovadas em relação aos 12 eixos temáticos mencionados (Brasil, 2005c). Esse conjunto de propostas foi reunido e encaminhado para a Secretaria Especial de Políticas de Promoção da Igualdade Racial (Seppir) para subsidiar a elaboração do Planappir.

Não obstante a variação no desenho institucional da $1^{\text {a }}$ CAP, $1^{\text {a }}$ Concidades, $1^{\text {a }}$ CMA, $1^{\text {a }} \mathrm{CE}, 1^{\mathrm{a}} \mathrm{CPM}$ e $1^{\mathrm{a}} \mathrm{CPIR}$, delas resultou um caderno de recomendações, cunhado a partir de um texto-base com propostas sugeridas pela instituição governamental competente, o qual retornou a esta para servir como referência para seu plano de ação nos anos seguintes. Tendo isso em mente, na próxima seção, apresenta-se o método delineado para aferir a capacidade de influência da $1^{\text {a }}$ CAP, $1^{\text {a }}$ Concidades, $1^{\text {a }}$ CMA, $1^{\text {a }}$ $\mathrm{CE}, 1^{\text {a }}$ CPM e $1^{\text {a }}$ CPIR sobre as respectivas políticas setoriais. 


\section{Metodologia de análise da capacidade de influência de conferências sobre as respectivas políticas setoriais}

As conferências de políticas públicas têm sido convocadas, dentre outros motivos, para discutir e produzir diretrizes para as políticas que debatem. Esses encontros têm debatido os programas das respectivas políticas setoriais e aprovado recomendações que compreendem desde pressupostos e objetivos até metas e ações para estas. Diante disso, a capacidade de influência da $1^{\text {a }} \mathrm{CAP}, 1^{\mathrm{a}}$ Concidades, $1^{\mathrm{a}} \mathrm{CMA}, 1^{\mathrm{a}} \mathrm{CE}, 1^{\mathrm{a}} \mathrm{CPM}$ e $1^{\mathrm{a}}$ CPIR sobre as respectivas políticas foi avaliada a partir dos efeitos das recomendações aprovadas nesses encontros sobre os programas de políticas formulados pelo governo federal após a realização das respectivas conferências. Esse efeito foi aferido por meio de comparação entre o conteúdo das recomendações das conferências e o conteúdo dos programas de políticas, e pela classificação do tipo de efeito, se nulo, parcial ou total, das recomendações sobre os programas. Neste artigo, o conteúdo foi entendido como o objetivo, a finalidade, a intenção expressa na recomendação, e não como a redação ipsis litteris do texto em si. O Quadro 1 traz exemplos dessa análise quanto ao conteúdo em relação a três conferências:

\section{Quadro 1}

\section{Exemplos do tipo de efeito (nulo, parcial ou total) do conteúdo das recomendações sobre os programas das respectivas políticas}

\begin{tabular}{|c|c|c|c|}
\hline Conferência & $\begin{array}{l}\text { Conteúdo da } \\
\text { recomendação }\end{array}$ & Conteúdo do programa & $\begin{array}{l}\text { Tipo de } \\
\text { efeito }\end{array}$ \\
\hline $1^{\text {a }}$ CAP & $\begin{array}{l}\text { Promover a propaganda e o } \\
\text { marketing do pescado oriundo } \\
\text { da aquicultura e da pesca } \\
\text { ressaltando os benefícios do } \\
\text { consumo de pescado para a } \\
\text { saúde. }\end{array}$ & $\begin{array}{l}\text { Promover a propaganda e o } \\
\text { marketing do pescado oriundo } \\
\text { da aquicultura e da pesca } \\
\text { ressaltando os benefícios do } \\
\text { consumo de pescado para a } \\
\text { saúde. }\end{array}$ & Total \\
\hline $1^{\text {a }}$ Concidades & $\begin{array}{l}\text { Desburocratizar e descentrali- } \\
\text { zar os programas federais. }\end{array}$ & e & Nulo \\
\hline $1^{\text {a }}$ CPM & $\begin{array}{l}\text { Estimular o compartilhamento } \\
\text { de tarefas domésticas através } \\
\text { de uma maior liberação do } \\
\text { tempo das trabalhadoras que } \\
\text { não incida na remuneração e } \\
\text { de campanhas institucionais, } \\
\text { construindo e reforçando uma } \\
\text { nova cultura referente à } \\
\text { divisão sexual do trabalho. }\end{array}$ & $\begin{array}{l}\text { Garantir o cumprimento da } \\
\text { legislação no âmbito do } \\
\text { trabalho doméstico e estimular } \\
\text { a divisão das tarefas } \\
\text { domésticas. }\end{array}$ & Parcial \\
\hline
\end{tabular}

Fonte: Formulação própria a partir do caderno de resoluções da $1^{a}$ CAP (Brasil, 2003a), $1^{a}$ Concidades (Brasil, 2003e), $1^{\text {a }}$ CMA (Brasil, 2003i), $1^{\text {a }}$ CE (Brasil, 2004e), dos Anais da $1^{\text {a }}$ CPM (Brasil, 2004g) e dos Anais da $1^{\text {a }}$ CPIR (Brasil, 2005c).

Para empregar tal análise, foi criado um banco de dados contendo as

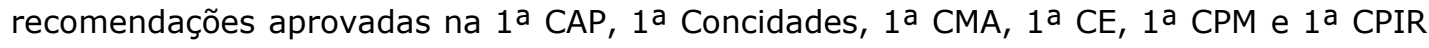
e o conteúdo dos programas de políticas formulados pelos respectivos ministérios após 
os encontros. Nas seis áreas, o ministério ou a secretaria especial elaborou um plano de ação logo após essas conferências, contendo os programas, ações e metas para essas políticas a ser implementados nos anos seguintes. Tanto o caderno de recomendações de cada conferência quanto os respectivos planos de ação foram obtidos por meio da Lei de Acesso à Informação e já se encontram disponíveis nos sites do Ministério da Pesca e Aquicultura $^{4}$ (Brasil, 2013b), MCidades (Brasil, 2013c), MMA (Brasil, 2005a), ME (Brasil, 2013d), SPM (Brasil, 2013e) Seppir (Brasil, 2013f).

Antes, porém, de realizar a comparação entre as recomendações de cada conferência e os programas governamentais, as primeiras foram avaliadas segundo o critério de competência e de forma de incorporação. A classificação por competência se justifica uma vez que essas áreas de políticas passaram pelo processo de descentralização administrativa nas décadas de 1980 e 1990, o qual, por sua vez, ampliou o leque de instituições corresponsáveis pela gestão dessas áreas. Por seu turno, a classificação por forma de incorporação permitiu identificar e excluir da análise as recomendações das conferências cuja incorporação passava pela elaboração de lei de iniciativa do Executivo ou do Legislativo, e não pela tradução desta em objetivo, princípio e/ou ação de programas do plano de ação do(s) ministério(s) competente(s).

Em relação à competência, as recomendações das conferências foram consideradas:

(0) de competência exclusiva da Seap, MCidades, MMA, ME, SPM e Seppir;

(1) de competência compartilhada entre a Seap, MCidades, MMA, ME, SPM, Seppir e outros ministérios e/ou unidades federativas; ou

(2) de competência exclusiva de outros ministérios, estados ou municípios.

Tal classificação baseou-se em duas fontes de informação: o Plano Plurianual 2004-2007 e os planos de ação analisados. Em ambos, há citação dos órgãos competentes por programa. Esse procedimento possibilitou a identificação e a exclusão da análise das propostas de competência externa, as quais não seriam incorporadas pela Seap, MCidades, MMA, ME, SPM e Seppir, mas encaminhadas para as instituições competentes após as conferências, por não se constituírem atribuições daqueles órgãos.

Identificadas as diretrizes de competência exclusiva e compartilhada da Seap, MCidades, MMA, ME, SPM e Seppir e excluídas as de competência externa, aplicou-se o segundo critério, qual seja, o da forma de incorporação de cada proposta. Assim, buscou-se identificar, dentre as recomendações de competência desses ministérios, aquelas cuja incorporação não se daria em um programa específico, mas requereria a edição de atos normativos, particularmente, instruções normativas e portarias, de competência de ministros e/ou conselhos nacionais. Nesse sentido, as recomendações foram classificadas como:

\footnotetext{
${ }^{4}$ À época da realização da $1^{\text {a }}$ CAP, existia a Secretaria Especial de Aquicultura e Pesca - Seap. Esta foi transformada no MPA em 2009 por decreto presidencial (Brasil, 2013b).
} 
(0) de incorporação via atos normativos; ou

(1) de incorporação via programas de políticas.

Uma vez que o escopo analítico deste artigo se limita aos efeitos das recomendações das conferências sobre os programas de políticas, as diretrizes de incorporação via atos normativos (1) foram retiradas do banco de dados. Assim, toda recomendação cuja finalidade consistia em "proibir certas práticas, regulamentar, regularizar e/ou criar e revisar leis, critérios, instrumentos e mecanismos de regulação" foi excluída da análise a fim de evitar constatações espúrias acerca da capacidade de influência de determinada conferência sobre a respectiva política.

A Tabela 1 apresenta a distribuição de recomendações por competência e por forma de incorporação, assim como o total de recomendações avaliadas por conferência examinada. Do total de 2.528 recomendações aprovadas na $1^{\text {a }}$ CAP, $1^{\text {a }}$ Concidades, $1^{\text {a }}$ CMA, $1^{\mathrm{a}} \mathrm{CE}, 1^{\mathrm{a}} \mathrm{CPM}$ e $1^{\mathrm{a}} \mathrm{CPIR}$, foram avaliadas 1.648 de competência exclusiva e compartilhada da Seap, MCidades, MMA, ME, SPM e Seppir e passíveis de incorporação em programas das respectivas políticas setoriais:

Tabela 1

Número de recomendações aprovadas e examinadas da $1^{\text {a }}$ CAP, $1^{\text {a }}$ Concidades, $1^{\text {a }}$ CMA, $1^{\text {a }}$ CE, $1^{\text {a }}$ CPM e $1^{a}$ CPIR por competência e forma de incorporação

\begin{tabular}{|c|c|c|c|c|c|c|}
\hline \multirow{2}{*}{ Conferência } & \multicolumn{3}{|c|}{ Tipo de competência } & \multicolumn{2}{|c|}{ Forma de incorporação } & \multirow{2}{*}{$\begin{array}{c}\text { Total de } \\
\text { recomendações } \\
\text { examinadas }\end{array}$} \\
\hline & Exclusiva & Compartilhada & Externa & $\begin{array}{l}\text { Programas } \\
\text { de políticas }\end{array}$ & $\begin{array}{c}\text { Atos } \\
\text { normativos }\end{array}$ & \\
\hline $1^{\mathrm{a}} \mathrm{CAP}$ & 100 & 65 & 10 & 154 & 11 & 154 \\
\hline $1^{\text {a }}$ Concidades & 127 & 126 & 45 & 239 & 14 & 239 \\
\hline $1^{\mathrm{a}} \mathrm{CMA}$ & 185 & 267 & 192 & 407 & 45 & 407 \\
\hline $1^{\text {a } C E}$ & 58 & 45 & 0 & 87 & 16 & 87 \\
\hline $1^{\mathrm{a}} \mathrm{CPM}$ & 19 & 118 & 116 & 131 & 6 & 131 \\
\hline $1^{\text {a }}$ CPIR & 141 & 611 & 303 & 630 & 122 & 630 \\
\hline Total & 712 & 1.150 & 666 & 1.648 & 214 & 1.648 \\
\hline
\end{tabular}

Fonte: Formulação própria com base no caderno de resoluções $1^{a}$ CAP (Brasil, 2003c), da $1^{a}$ Concidades (Brasil 2003e), $1^{\text {a }}$ CMA (Brasil, 2003h, 2003i), $1^{\text {a }}$ CE (Brasil, 2004e), $1^{\text {a }}$ CPM (Brasil, 2004g) e $1^{\text {a }}$ CPIR (Brasil, 2005c).

No que se refere ao tipo de competência, a quantidade de recomendações de competência compartilhada aprovada, 1.150 propostas, representou mais de $45 \%$ do total, o que confirma o caráter descentralizado das seis políticas setoriais examinadas. Nesse aspecto, vale destacar o número expressivo e maior de propostas compartilhadas aprovadas na $1^{\text {a }}$ CMA, $1^{\text {a }}$ CPM e $1^{\text {a }}$ CPIR em relação às exclusivas e externas. Também chama atenção a quantidade significativa de recomendações externas aprovadas nessas três conferências, comparativamente à dos demais encontros.

Quanto à forma de incorporação, observa-se um número reduzido de propostas sujeitas a atos normativos - 214 no total, comparativamente à quantidade passível de 
incorporação em programas de políticas - 1.648 no total. Esse dado não surpreende porém, haja vista que as conferências foram convocadas pelo Executivo para debater as políticas por ele elaboradas e implementadas.

Tendo identificado as recomendações passíveis de ser incorporadas em programas de políticas públicas da Seap, MCidades, MMA, ME, SPM e Seppir, o passo seguinte foi classificá-las em recomendações sugeridas pela comissão organizadora e propostas inéditas, elaboradas ao longo do processo conferencial. Nesse sentido, as sugestões contidas no caderno-base de discussão na conferência foram incluídas no banco de dados e comparadas às recomendações finais de modo a identificar as propostas aprovadas sugeridas e inéditas. Assim como o caderno de resoluções da conferência e o plano de ação da respectiva política, o texto-base dessas conferências foi obtido ou pelo portal de acesso à informação ou no site do ministério sede do encontro (Brasil, 2003d, 2003g, 2003j, 2004f, 2004h, 2005d).

Antes, porém, de empreender tal análise, as sugestões foram classificadas por competência e forma de incorporação, de modo a identificar aquelas cuja incorporação competiria a outros entes federativos exclusivamente ou não se traduziria em componente do plano de ação, mas passaria pela edição de atos normativos, notadamente, instruções normativas e portarias de ministros e/ou conselhos nacionais. A Tabela 2 traz os resultados dessa análise. Como pode ser visto, nenhuma sugestão encaminhada competia unicamente a outras instituições ou entes da Federação e poucas delas requeriam a elaboração de atos normativos, tendo sido excluídas da análise:

Tabela 2

Sugestões encaminhadas a $1^{\text {a }}$ CAP, $1^{\text {a }}$ Concidades, $1^{\text {a }}$ CMA, $1^{\text {a }}$ CE, $1^{\text {a }}$ CPM e $1^{\text {a }}$ CPIR por competência e forma de incorporação

\begin{tabular}{|c|c|c|c|c|c|c|}
\hline \multirow[b]{2}{*}{ Conferência } & \multicolumn{3}{|c|}{ Tipo de competência } & \multicolumn{2}{|c|}{ Forma de incorporação } & \multirow{2}{*}{$\begin{array}{c}\text { Total de } \\
\text { sugestões } \\
\text { examinadas }\end{array}$} \\
\hline & Exclusiva & Compartilhada & Externa & $\begin{array}{c}\text { Programas } \\
\text { de } \\
\text { políticas }\end{array}$ & $\begin{array}{c}\text { Atos } \\
\text { normativos }\end{array}$ & \\
\hline $1^{\text {a }}$ CAP & 63 & 31 & 0 & 91 & 3 & 91 \\
\hline $\begin{array}{l}1^{\mathrm{a}} \\
\text { Concidades }\end{array}$ & 60 & 40 & 0 & 90 & 10 & 90 \\
\hline $1^{\text {a }} \mathrm{CMA}$ & 65 & 44 & 0 & 93 & 16 & 93 \\
\hline $1^{\text {a }} \mathrm{CE}$ & 82 & 37 & 0 & 97 & 22 & 97 \\
\hline $1^{\text {a }}$ CPM & 5 & 36 & 0 & 28 & 13 & 28 \\
\hline $1^{\text {a }}$ CPIR & 15 & 58 & 0 & 61 & 12 & 61 \\
\hline Total & 290 & 246 & 0 & 460 & 76 & 460 \\
\hline
\end{tabular}

Fonte: Formulação própria a partir do texto-base da $1^{\text {a }}$ CAP (Brasil, 2003d), $1^{\text {a }}$ Concidades (Brasil,2003g), $1^{\text {a }}$ CMA (Brasil, 2003j), $1^{\text {a }}$ CE (Brasil, 2004f), $1^{\text {a }}$ CPM (Brasil, 2004h) e $1^{\text {a }}$ CPIR (Brasil, 2005d).

O Projeto Político da Seap, encaminhado à $1^{\text {a }}$ CAP, foi composto por 94 sugestões, sendo 63 de competência exclusiva desse órgão e 31, compartilhadas. Destas, apenas três requeriam a edição de atos normativos e não foram avaliadas. Por seu turno, o 
texto-base da $1^{\text {a }}$ Concidades foi composto por 100 sugestões, das quais 60 competiam exclusivamente ao MCidades e 40, a essa instituição e outros órgãos ou unidades federativas. Desse total, 10 requeriam a edição de atos normativos para ser incorporadas e foram, portanto, retiradas do banco de dados. Das 109 sugestões do MMA à $1^{\text {a }}$ CMA 65 exclusivas e 44 compartilhadas, 16 foram eliminadas do banco de dados, uma vez que dependiam da elaboração de atos normativos para ser incluídas. Já o texto-base da $1^{a}$ CE foi composto por 119 sugestões, sendo 97 delas analisadas por serem de competência do ME e passíveis de incorporação em programas da política nacional de esporte. O caderno de sugestões encaminhado pela SPM à $1^{\text {a }}$ CPM, por sua vez, continha 41 recomendações, dentre as quais 13 requeriam a edição de atos normativos para ser incluídas. Por fim, das 15 sugestões de competência exclusiva e das 58 de competência compartilhada da Seppir, 61 eram de competência da Seppir e foram examinadas neste artigo.

Identificadas as recomendações sugeridas de competência da Seap, MCidades, MMA, ME, SPM e Seppir e passíveis de incorporação no Plano de Ação dessas instituições, estas foram comparadas às recomendações finais da $1^{a}$ CAP, $1^{a}$ Concidades, $1^{a}$ CMA, $1^{a}$ CE, $1^{\text {a }}$ CPM e $1^{\text {a }}$ CPIR, a fim de identificar as propostas inéditas, isto é, que teriam emergido ao longo do processo conferencial. A cada recomendação analisada foi atribuído valor:

- 0 , quando o conteúdo da recomendação final correspondia parcialmente ao conteúdo de sugestões encaminhadas à conferência;

- 1 , quando o conteúdo da recomendação final correspondia integralmente ao conteúdo de sugestões encaminhadas à conferência; ou

- 2, quando o conteúdo da recomendação final não correspondia ao conteúdo de nenhuma sugestão encaminhada à conferência, sendo, portanto, inédito.

Feito isso, cada recomendação foi comparada individualmente com os princípios, objetivos, ações, entre outros componentes, dos programas de políticas lançados após a $1^{\text {a } C A P}, 1^{\text {a }}$ Concidades, $1^{\text {a }}$ CMA $, 1^{\text {a }} \mathrm{CE}, 1^{\text {a }}$ CPM e $1^{\text {a }}$ CPIR e classificadas com o valor:

- 0 , quando o conteúdo da recomendação não foi incluído em nenhum dos programas (efeito nulo);

- 1 , quando o conteúdo da recomendação foi incluído parcialmente nos programas (efeito parcial); e

- 2, quando o conteúdo da recomendação foi incluído integralmente nos programas (efeito total).

Dessa comparação, foi aferida a capacidade total de influência da $1^{\text {a }}$ CAP, $1^{\text {a }}$ Concidades, $1^{\text {a } C M A}, 1^{\text {a }} \mathrm{CE}, 1^{\text {a }} \mathrm{CPM}$ e $1^{\text {a }}$ CPIR sobre as respectivas políticas, calculandose a quantidade percentual de propostas sugeridas e inéditas incluídas, parcial ou integralmente, no total aprovado em cada encontro. A capacidade total de influência 
desses processos foi considerada:

a) nula, quando nenhuma das recomendações foi introduzida pelo governo; em outras palavras, $100 \%$ das diretrizes aprovadas receberam valor 0 ;

b) baixa, quando de $1 \%$ a $30 \%$ das recomendações aprovadas foram introduzidas pelo governo, parcial ou integralmente;

c) média, quando de $31 \%$ a $70 \%$ das recomendações foram introduzidas pelo governo, parcial ou integralmente; ou

d) alta, quando de $71 \%$ a $100 \%$ das recomendações foram introduzidas pelo governo, parcial ou integralmente.

Mediante o impacto das propostas sugeridas sobre as recomendações finais das conferências e sobre os programas das políticas setoriais, tomou-se o cuidado de avaliar a real capacidade de influência das conferências sobre os programas das respectivas políticas, dada pela proporção relativa de recomendações inéditas incluídas em relação ao total de propostas aprovadas e incorporadas aos programas da política setorial. Tal qual realizado para a capacidade total de influência, a capacidade real foi classificada como:

a) nula, quando todas as recomendações incluídas resultaram de sugestões governamentais aprovadas nas conferências;

b) baixa, quando as recomendações inéditas incluídas corresponderam apenas de $1 \%$ a $30 \%$ do total de recomendações introduzidas pelo governo;

c) média, quando as recomendações inéditas incluídas corresponderam de $31 \%$ a $70 \%$ do total de recomendações incluídas pelo governo; ou

d) alta, quando as recomendações inéditas corresponderam de $71 \%$ a $100 \%$ do total de recomendações incluídas, em alguma medida, pelo governo.

Os programas de política resultantes de processos conferenciais cuja capacidade real de influência foi baixa apresentaram alto teor governamental, ao passo que os programas decorrentes de conferências com alta capacidade de influência apresentaram grande lastro societário. Quando, porém, a capacidade de influência da conferência foi média, os programas por ela influenciados foram considerados "partilhados", haja vista sua composição mista, com propostas governamentais e societais.

Os resultados obtidos em relação à capacidade total de influência da $1^{\text {a }} \mathrm{CAP}, 1^{\mathrm{a}}$ Concidades, $1^{\text {a }}$ CMA, $1^{\text {a }} \mathrm{CE}, 1^{\text {a }}$ CPM e $1^{\text {a }}$ CPIR são apresentados e analisados a seguir.

\section{Aferindo a capacidade de influência da $1^{\text {a }}$ CAP, $1^{\text {a }}$ Concidades, $1^{\text {a }}$ CMA, $1^{\text {a }}$ CE, $1^{\text {a }}$ CPM e da $1^{\text {a }}$ CPIR sobre as respectivas políticas setoriais}

As discussões e decisões tomadas na $1^{\text {a }}$ CAP, $1^{\text {a }}$ Concidades, $1^{\text {a }}$ CMA, $1^{\text {a }} \mathrm{CE}, 1^{\text {a }}$ CPM e $1^{\text {a }}$ CPIR se deram a partir de um texto-base, elaborado pela comissão 
organizadora da conferência. Nele, estavam listadas as diretrizes básicas para as subáreas de intervenção governamental no âmbito de cada política setorial. Das 460 sugestões aqui examinadas, 340,74\% do total, foram traduzidas em recomendações da $1^{\text {a } C A P}, 1^{\text {a }}$ Concidades, $1^{\text {a } C M A}, 1^{\text {a }} \mathrm{CE}, 1^{\text {a }}$ CPM e $1^{\text {a }}$ CPIR em alguma medida, conforme mostra a Tabela 3. Nos seis processos conferenciais, o total de sugestões aprovadas superou o de sugestões que não passaram pelo crivo dos delegados presentes. Na $1^{a}$ Concidades, somente $4,5 \%$ das sugestões governamentais não foram aprovadas, seguida pela $1^{\text {a }}$ CPIR, com $15 \%$ de reprovação apenas.

Tabela 3

Sugestões não aprovadas e aprovadas pelos delegados da $1^{\text {a }}$ CAP, $1^{\text {a }}$ Concidades, $1^{\text {a }}$ CMA, $1^{\text {a }}$ CE, $1^{\text {a }}$ CPM e $1^{\text {a }}$ CPIR

\begin{tabular}{|c|c|c|c|c|c|c|}
\hline \multirow{3}{*}{ Conferência } & \multicolumn{4}{|c|}{ Sugestões } & \multirow{2}{*}{\multicolumn{2}{|c|}{ Total geral }} \\
\hline & \multicolumn{2}{|c|}{ Não aprovadas } & \multicolumn{2}{|c|}{ Aprovadas } & & \\
\hline & $\mathbf{N}$ & $\%$ & $\mathbf{N}$ & $\%$ & $\mathbf{N}$ & $\%$ \\
\hline $1^{a}$ CAP & 30 & 33,0 & 61 & 67,0 & 91 & 100 \\
\hline $1^{\text {a }}$ Concidades & 4 & 4,5 & 86 & 95,5 & 90 & 100 \\
\hline $1^{\mathrm{a}} \mathrm{CMA}$ & 20 & 21,5 & 73 & 78,5 & 93 & 100 \\
\hline $1^{\mathrm{a}} \mathrm{CE}$ & 46 & 47,5 & 51 & 52,5 & 97 & 100 \\
\hline $1^{\mathrm{a}} \mathrm{CPM}$ & 11 & 39,5 & 17 & 60,5 & 28 & 100 \\
\hline $1^{\mathrm{a}}$ CPIR & 9 & 15,0 & 52 & 85,0 & 61 & 100 \\
\hline Total & 120 & 26,0 & 340 & 74,0 & 460 & 100 \\
\hline
\end{tabular}

Fonte: Formulação própria a partir do caderno de resoluções e do texto-base da $1^{\text {a }}$ CAP

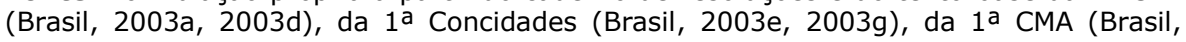
2003i, 2003j), da $1^{\text {a }}$ CE (Brasil, 2004e, 2004f), da $1^{\text {a }}$ CPM (Brasil, 2004g, 2004h) e da $1^{\text {a }}$ CPIR (Brasil, 2005c, 2005d).

Das 340 sugestões governamentais aprovadas nas seis conferências, a Tabela 4 mostra que 245 (72\%) foram aprovadas com modificações pelos delegados participantes e somente 95 sugestões (28\%) passaram pelo crivo destes sem alterações. Nos seis processos conferenciais, a proporção de sugestões aprovadas integralmente foi inferior à de sugestões aprovadas parcialmente, variando entre 3,5\% para a $1^{\text {a }}$ CPM e $33 \%$ para a $1^{\text {a }}$ CAP. Disso se observa a riqueza do debate e a diversidade de opiniões e interesses dos atores neles participantes. Embora a discussão e a elaboração de diretrizes na $1^{a}$ CAP, $1^{\text {a }}$ Concidades, $1^{\text {a }}$ CMA, $1^{\text {a }} \mathrm{CE}, 1^{\text {a }}$ CPM e $1^{\text {a }}$ CPIR tenham sido pautadas e influenciadas por um conjunto de sugestões governamentais, estas não impediram que parte expressiva das ideias ali debatidas se misturasse e resultasse em novas propostas para os ministérios competentes. 
Tabela 4

Sugestões aprovadas parcial e integralmente pelos delegados da $1^{\text {a }}$ CAP, $1^{\text {a }}$ Concidades, $1^{\text {a }}$ CMA, $1^{\text {a }}$ CE, $1^{\text {a }}$ CPM e $1^{\text {a }}$ CPIR

\begin{tabular}{|c|c|c|c|c|c|c|}
\hline \multirow{3}{*}{ Conferência } & \multicolumn{4}{|c|}{$\begin{array}{c}\text { Sugestões } \\
\end{array}$} & \multirow{2}{*}{\multicolumn{2}{|c|}{ Total }} \\
\hline & \multicolumn{2}{|c|}{$\begin{array}{c}\text { Aprovadas } \\
\text { parcialmente }\end{array}$} & \multicolumn{2}{|c|}{$\begin{array}{c}\text { Aprovadas } \\
\text { integralmente }\end{array}$} & & \\
\hline & $\mathbf{N}$ & $\%$ & $\mathbf{N}$ & $\%$ & $\mathbf{N}$ & $\%$ \\
\hline $1^{\mathrm{a}} \mathrm{CAP}$ & 28 & 46,0 & 33 & 54,0 & 61 & 100,0 \\
\hline $1^{\text {a }}$ Concidades & 60 & 70,0 & 26 & 30,0 & 86 & 100,0 \\
\hline $1^{\mathrm{a}} \mathrm{CMA}$ & 66 & 90,0 & 7 & 10,0 & 73 & 100,0 \\
\hline $1^{\mathrm{a}} \mathrm{CE}$ & 33 & 65,0 & 18 & 35,0 & 51 & 100,0 \\
\hline $1^{\mathrm{a}} \mathrm{CPM}$ & 16 & 94,0 & 1 & 6,0 & 17 & 100,0 \\
\hline $1^{\mathrm{a}}$ CPIR & 42 & 81,0 & 10 & 19,0 & 52 & 100,0 \\
\hline Total & 245 & 72,0 & 95 & 28,0 & 340 & 100,0 \\
\hline
\end{tabular}

Fonte: Formulação própria a partir do caderno de resoluções e do texto-base da $1^{a}$ CAP (Brasil, 2003a, 2003d), da $1^{\text {a }}$ Concidades (Brasil, 2003e, 2003g), da $1^{\text {a }}$ CMA (Brasil, 2003i, 2003j), da $1^{\text {a }}$ CE (Brasil, 2004e, 2004f), da $1^{\text {a }}$ CPM (Brasil, 2004g, 2004h) e da $1^{\text {a }}$ CPIR (Brasil, 2005c, 2005d).

As 340 sugestões aprovadas parcial ou integralmente pelos delegados da $1^{\text {a }}$ CAP,

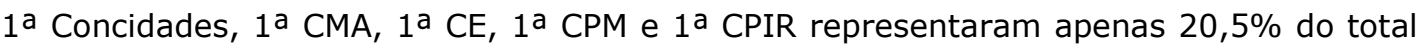
das recomendações por eles aprovadas nesses processos conferenciais (Tabela 5). Das 1.648 recomendações aqui analisadas, 1.308, o que corresponde a 79,5\% do total, foram elaboradas, de forma inédita, pelos participantes ao longo desses processos conferenciais:

Tabela 5

Propostas sugeridas e inéditas aprovadas na $1^{\text {a }}$ CAP, $1^{\text {a }}$ Concidades, $1^{\text {a }}$ CMA, $1^{\text {a }}$ CE, $1^{\text {a }}$ CPM e $1^{\text {a }}$ CPIR

\begin{tabular}{|c|c|c|c|c|c|c|}
\hline \multirow[t]{2}{*}{ Conferência } & \multicolumn{2}{|c|}{$\begin{array}{c}\text { Propostas } \\
\text { aprovadas (A) }\end{array}$} & \multicolumn{2}{|c|}{$\begin{array}{c}\text { Propostas } \\
\text { sugeridas } \\
\text { (B) }\end{array}$} & \multicolumn{2}{|c|}{$\begin{array}{c}\text { Propostas } \\
\text { inéditas } \\
\text { (A-B) }\end{array}$} \\
\hline & $\mathbf{N}$ & $\%$ & $\mathbf{N}$ & $\%$ & $\mathbf{N}$ & $\%$ \\
\hline $1^{a} \mathrm{CAP}$ & 154 & 100,0 & 61 & 39,5 & 93 & 60,5 \\
\hline $1^{\text {a }}$ Concidades & 239 & 100,0 & 86 & 36,0 & 153 & 64,0 \\
\hline $1^{a} \mathrm{CMA}$ & 407 & 100,0 & 73 & 18,0 & 334 & 82,0 \\
\hline $1^{a} \mathrm{CE}$ & 87 & 100,0 & 51 & 58,5 & 36 & 41,5 \\
\hline $1^{a}$ CPM & 131 & 100,0 & 17 & 13,0 & 114 & 87,0 \\
\hline $1^{\mathrm{a}}$ CPIR & 630 & 100,0 & 52 & 8,5 & 578 & 91,5 \\
\hline Total & 1.648 & 100,0 & 340 & 20,5 & 1.308 & 79,5 \\
\hline
\end{tabular}

Fonte: Formulação própria a partir do caderno de resoluções e do texto-base da $1^{\text {a }}$ CAP (Brasil, 2003a, 2003d), da $1^{\text {a }}$ Concidades (Brasil, 2003e, 2003g), da $1^{\text {a }}$ CMA (Brasil, 2003i, 2003j), da $1^{\text {a }}$ CE (Brasil, 2004e, 2004f), da $1^{\text {a }}$ CPM (Brasil, 2004g, 2004h) e da $1^{\text {a }}$ CPIR (Brasil, 2005c, 2005d).

No que diz respeito especificamente às 340 sugestões aprovadas, verifica-se uma variação expressiva na quantidade destas por encontro. Enquanto as sugestões aprovadas na $1^{\text {a }}$ CPIR representaram somente $8,5 \%$ do total de recomendações finais desse encontro, na $1^{\mathrm{a}} \mathrm{CE}$, as sugestões representaram quase $60 \%$ do total aprovado. 
Nas demais quatro conferências, $1^{\text {a } C A P,} 1^{\text {a }}$ Concidades, $1^{\text {a }}$ CMA e $1^{\text {a }}$ CPM, as sugestões governamentais corresponderam a menos de $40 \%$ do total de propostas aprovadas.

Por outro lado, no que concerne ao total de recomendações inéditas, a Tabela 5 aponta que a maior quantidade delas ( $91,5 \%$ do total) foi produzida ao longo da $1^{\text {a }}$ CPIR, seguida pela $1^{\text {a }}$ CPM, com $87 \%$ do total de propostas inéditas aprovadas, e pela $1^{\text {a }}$ CMA, com $82 \%$. Menos de $50 \%$ de recomendações inéditas foram aprovadas na $1^{\text {a }}$ CE $41,5 \%$.

Das 1.648 recomendações avaliadas, 746 (45\%) não foram incorporadas, em nenhuma medida, pela Seap, MCidades, MMA, ME, SPM e Seppir nos anos subsequentes a $1^{\text {a }}$ Concidades, $1^{\text {a }}$ CAP, $1^{\text {a }}$ CMA, $1^{\text {a }} \mathrm{CE}, 1^{\text {a }}$ CPM e $1^{\text {a }}$ CPIR (Tabela 6). Das 902 recomendações incorporadas aos programas de políticas (55\%), 691, o que corresponde a $76,5 \%$ do total, foram incorporadas integralmente, tal como aprovadas nesses encontros, e o restante, 211 recomendações (23,5\%), foram parcialmente atendidas e convertidas em ações dos respectivos ministérios competentes. Da $1^{\text {a }}$ CAP, a totalidade de recomendações aprovadas foi incorporada sem alterações, enquanto, da $1^{\text {a }}$ CPIR, somente $23 \%$ foram traduzidas integralmente no I Planappir. No que se refere às recomendações parcialmente incorporadas, a variação foi significativamente menor. Salvo para a $1^{\text {a }}$ CAP, das demais conferências, entre $13 \%$ e $16 \%$ das recomendações aprovadas foram incluídas parcialmente.

\section{Tabela 6}

Recomendações aprovadas na $1^{\text {a }}$ CAP, $1^{\text {a }}$ Concidades, $1^{\text {a }}$ CMA, $1^{\text {a }}$ CE, $1^{\text {a }}$ CPM e $1^{\text {a }}$ CPIR incluídas parcial ou integralmente nos programas dessas políticas

\begin{tabular}{|c|c|c|c|c|c|c|c|c|}
\hline \multirow{4}{*}{ Conferência } & \multicolumn{6}{|c|}{ Recomendações } & \multirow{2}{*}{\multicolumn{2}{|c|}{$\begin{array}{c}\text { Capacidade } \\
\text { total de } \\
\text { influência }\end{array}$}} \\
\hline & \multirow{2}{*}{\multicolumn{2}{|c|}{ Não incluídas }} & \multirow{2}{*}{\multicolumn{2}{|c|}{$\begin{array}{c}\text { Incluídas } \\
\text { parcialmente } \\
\text { (A) }\end{array}$}} & \multirow{2}{*}{\multicolumn{2}{|c|}{$\begin{array}{c}\text { Incluídas } \\
\text { integralmente } \\
\text { (B) }\end{array}$}} & & \\
\hline & & & & & & & & B) \\
\hline & $\mathbf{N}$ & $\%$ & $\mathbf{N}$ & $\%$ & $\mathbf{N}$ & $\%$ & $\mathbf{N}$ & $\%$ \\
\hline $1^{a}$ CAP & 0 & 0,0 & 0 & 0,0 & 154 & 100,0 & 154 & 100,0 \\
\hline $1^{\text {a }}$ Concidades & 57 & 24,0 & 31 & 13,0 & 151 & 63,0 & 182 & 76,0 \\
\hline $1^{\mathrm{a}} \mathrm{CMA}$ & 217 & 53,0 & 53 & 13,0 & 137 & 33,5 & 190 & 46,5 \\
\hline $1^{a} \mathrm{CE}$ & 36 & 41,0 & 11 & 12,5 & 40 & 46,0 & 51 & 58,5 \\
\hline $1^{\mathrm{a}} \mathrm{CPM}$ & 52 & 40,0 & 15 & 11,5 & 64 & 49,0 & 79 & 60,5 \\
\hline $1^{\text {a }}$ CPIR & 384 & 61,0 & 101 & 16,0 & 145 & 23,0 & 246 & 39,0 \\
\hline Total & 746 & 45,0 & 211 & 13,0 & 691 & 42,0 & 902 & 55,0 \\
\hline
\end{tabular}

Fonte: Formulação própria a partir do caderno de resoluções da $1^{\text {a }}$ Concidades (Brasil, 2003e) e cadernos MCidades, volumes de 1 a 9 (Brasil, 2004b), do caderno de resoluções da 1a CAP (Brasil, 2003a) e do Plano Estratégico da Seap (Brasil, 2004a), do caderno de resoluções da 1a CMA (Brasil, 2003i), PPA 2004-2007 (Brasil, 2003k) e Ações do MMA (Brasil, 2005a), do caderno de resoluções da 1a CE (Brasil, 2004e) e Política Nacional de Esporte (Brasil, 2005b), dos Anais da $1^{\text {a }}$ CPM (Brasil, 2004g) e I PNPM (Brasil, 2004i), e Anais da $1^{\text {a }}$ CPIR (Brasil, 2005c) e I Planappir (Brasil, 2009).

Disso segue que nenhuma das conferências analisadas apresentou capacidade de influência nula ou baixa, segundo a classificação aqui proposta. Dois terços dos encontros, quais sejam, a $1^{\text {a }} \mathrm{CE}$, a $1^{\mathrm{a}} \mathrm{CMA}$, a $1^{\mathrm{a}} \mathrm{CPM}$ e a $1^{\mathrm{a}} \mathrm{CPIR}$, tiveram entre $31 \%$ e 
70\% de suas recomendações incluídas nos programas de ação do governo federal nos anos seguintes e, portanto, apresentaram média capacidade total de influência sobre as respectivas políticas. O outro terço dos encontros examinados, a saber, a $1^{\text {a }}$ CAP e a $1^{\text {a }}$ Concidades, teve mais de $71 \%$ de suas propostas incorporadas pelas instituições competentes, alcançando alta capacidade total de influência sobre as políticas de aquicultura e pesca e urbana.

Dentre as 902 recomendações incorporadas às políticas setoriais, 261 foram sugeridas pela comissão organizadora às seis conferências examinadas e 641 surgiram, de forma inédita, ao longo desses processos, como mostra o Gráfico 1. Das 340 sugestões aprovadas na $1^{\text {a } C A P}, 1^{\text {a }}$ Concidades, $1^{\text {a } C M A}, 1^{\text {a }}$ CE, $1^{\text {a }}$ CPM e $1^{\text {a }}$ CPIR, somente 79 , isto é, $23 \%$ do total, não foram traduzidas em ações da Seap, MCidades, MMA, ME, SPM e Seppir após passar pelo crivo dos delegados participantes das respectivas conferências. Por sua vez, das 1.308 recomendações inéditas aprovadas nos seis processos, 667 - $51 \%$ do total - não foram incorporadas, em nenhuma medida, nas políticas setoriais correspondentes.

\section{Gráfico 1 \\ Propostas sugeridas e inéditas incorporadas às respectivas políticas setoriais}

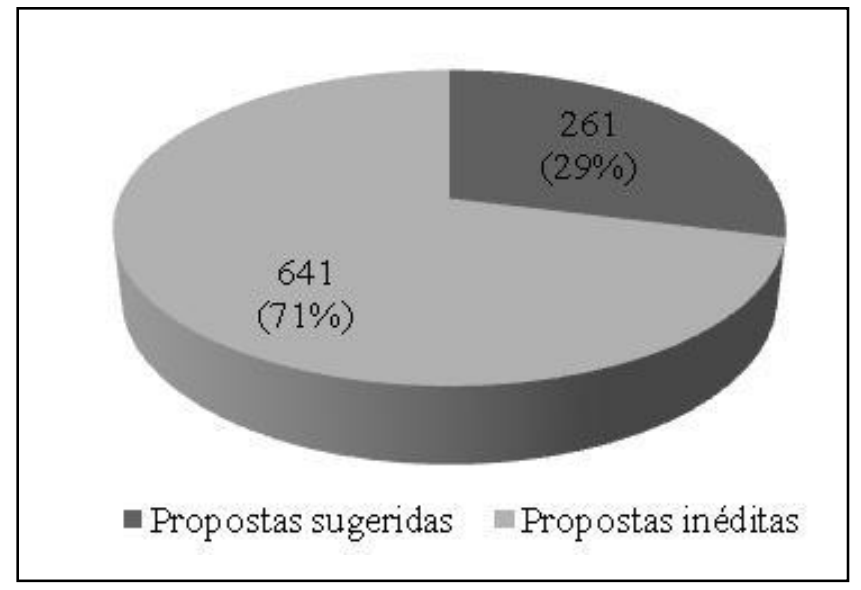

Fonte: Formulação própria a partir dos resultados da Tabela 6 .

Desagregando esses resultados por conferência e por tipo de recomendação, o que se observa, pela Tabela 7 , é que as sugestões aprovadas na $1^{\text {a }}$ CAP ( $100 \%$ do total), $1^{a}$ Concidades ( $89,5 \%$ do total) e $1^{\text {a }}$ CPM ( $88 \%$ do total) foram as mais incorporadas pelos ministérios competentes após esses processos. As sugestões aprovadas nas demais três conferências, $1^{\text {a }}$ CMA, $1^{\text {a }}$ CE e $1^{\text {a }}$ CPIR, foram incorporadas, em menor medida, mas em proporção próxima: da $1^{\text {a }} \mathrm{CMA}$, foram incorporadas $61,5 \%$ das sugestões nela 
aprovadas, seguida pela $1^{\text {a }} \mathrm{CE}$, com $65 \%$ de sugestões nela aprovadas e incluídas, e pela $1^{\text {a }}$ CPIR, com $57,5 \%$.

Da mesma forma, no que diz respeito às propostas inéditas, constata-se que as recomendações inéditas aprovadas na $1^{\text {a }}$ CAP $\left(100 \%\right.$ do total), $1^{\text {a }}$ Concidades $(68,5 \%$ do total) e $1^{\text {a }}$ CPM $(56,0 \%$ do total) foram as mais traduzidas nas respectivas políticas setoriais nos anos seguintes. Das demais três conferências, $1^{\text {a }}$ CMA, $1^{\text {a }}$ CE e $1^{\text {a }}$ CPIR, uma quantidade percentual menor de propostas inéditas foi incorporada, variando entre $37,5 \%$ para a $1^{\text {a }}$ CPIR e $50 \%$ para a $1^{\text {a }}$ CE (Tabela 7$)$ :

Tabela 7

Propostas sugeridas e inéditas aprovadas na $1^{\mathrm{a}} \mathrm{CAP}$, $1^{\text {a }}$ Concidades, $1^{\text {a }}$ CMA, $1^{\text {a }}$ CE, $1^{\text {a }}$ CPM e $1^{\text {a }}$ CPIR incluídas ou não nos programas da Seap, MCidades, MMA, ME, SPM e SEPPIR

\begin{tabular}{|c|c|c|c|c|c|c|c|c|}
\hline \multirow{3}{*}{ Conferência } & \multicolumn{4}{|c|}{ Propostas sugeridas } & \multicolumn{4}{|c|}{ Propostas inéditas } \\
\hline & \multicolumn{2}{|c|}{ Não incluídas } & \multicolumn{2}{|c|}{ Incluídas } & \multicolumn{2}{|c|}{ Não incluídas } & \multicolumn{2}{|c|}{ Incluídas } \\
\hline & $\mathbf{N}$ & $\%$ & $\mathbf{N}$ & $\%$ & $\mathbf{N}$ & $\%$ & $\mathbf{N}$ & $\%$ \\
\hline $1^{\mathrm{a}} \mathrm{CAP}$ & 0 & 0 & 61 & 100,0 & 0 & 0 & 93 & 100,0 \\
\hline $\begin{array}{l}1^{\mathrm{a}} \\
\text { Concidades }\end{array}$ & 9 & 10,5 & 77 & 89,5 & 48 & 31,5 & 105 & 68,5 \\
\hline $1^{\text {a }} \mathrm{CMA}$ & 28 & 38,5 & 45 & 61,5 & 189 & 56,5 & 145 & 43,5 \\
\hline $1^{\mathrm{a}} \mathrm{CE}$ & 18 & 35,0 & 33 & 65,0 & 18 & 50,0 & 18 & 50,0 \\
\hline $1^{\text {a }}$ CPM & 2 & 12,0 & 15 & 88,0 & 50 & 44,0 & 64 & 56,0 \\
\hline $1^{\text {a }}$ CPIR & 22 & 42,5 & 30 & 57,5 & 362 & 62,5 & 216 & 37,5 \\
\hline Total & 79 & 23,0 & 261 & 77,0 & 667 & 51,0 & 641 & 49,0 \\
\hline
\end{tabular}

Fonte: Formulação própria a partir do caderno de resoluções da $1^{\text {a }}$ Concidades (Brasil, 2003e) e cadernos MCidades, volumes de 1 a 9 (Brasil, 2004b), do caderno de resoluções da 1 a CAP (Brasil, 2003a) e do Plano Estratégico da Seap (Brasil, 2004a), do caderno de resoluções da 1a CMA (Brasil, 2003i), PPA 2004-2007 (Brasil, 2003k) e Ações do MMA (Brasil, 2005a), do caderno de resoluções da $1^{a}$ CE (Brasil, 2004e) e Política Nacional de Esporte (Brasil, 2005b), dos Anais da $1^{\text {a }}$ CPM (Brasil, 2004g) e I PNPM (Brasil, 2004i), e Anais da $1^{\text {a }}$ CPIR (Brasil, 2005c) e I Planappir (Brasil, 2009).

Quanto à forma de incorporação das 902 recomendações sugeridas e inéditas aprovadas e traduzidas no plano de ação da Seap, MCidades, MMA, ME, SPM e Seppir, o Gráfico 2 mostra que tanto as propostas sugeridas como as inéditas foram, em maior medida, incorporadas integralmente às políticas setoriais. Das 261 sugestões e 641 recomendações inéditas, 208 ( $80 \%$ do total de sugestões) e 486 (76\% do total de recomendações inéditas) foram incluídas tal qual aprovadas na $1^{\mathrm{a}} \mathrm{CAP}, 1^{\mathrm{a}}$ Concidades, $1^{\text {a }}$ CMA, $1^{\text {a }} \mathrm{CE}, 1^{\text {a }}$ CPM e $1^{\text {a }}$ CPIR. As demais 53 sugestões (20\% do total) e 155 propostas inéditas ( $24 \%$ do total) foram traduzidas no Plano de Ação com modificações: 


\section{Gráfico 2}

\section{Propostas sugeridas e inéditas incorporadas parcial e} integralmente às respectivas políticas

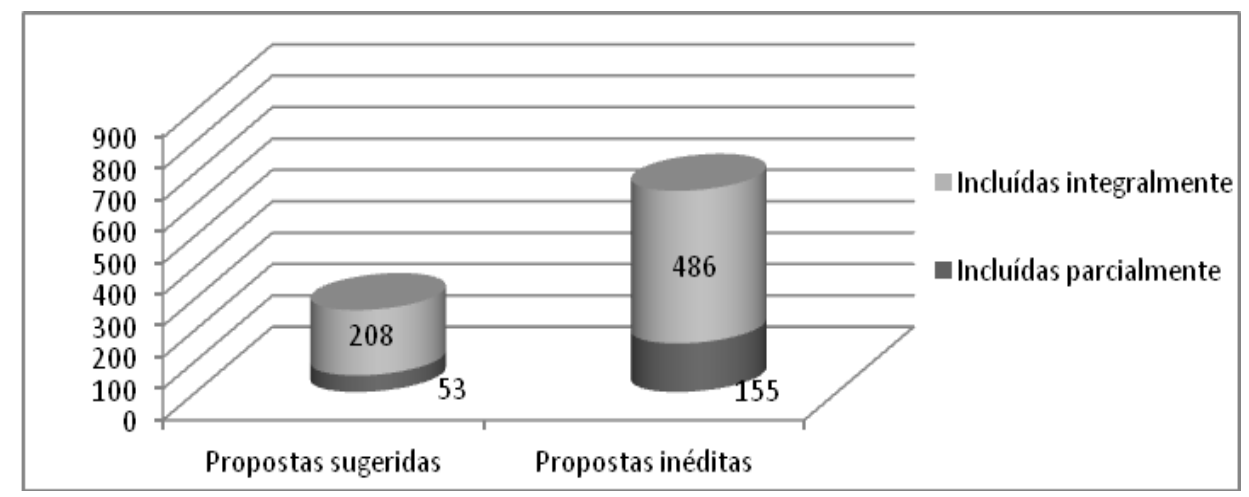

Fonte: Formulação própria a partir dos resultados da Tabela 7.

Desagregando esses resultados por conferência e forma de incorporação das recomendações (Tabela 8), o que se verifica é que a Seppir e o MMA foram os órgãos que mais incorporaram propostas sugeridas e recomendações inéditas parcialmente $53,5 \%$ e $40 \%$ do total de sugestões e $39,5 \%$ e $23 \%$ do total de recomendações inéditas, respectivamente. Já a Seap se destacou por ter incluído integralmente $100 \%$ das propostas sugeridas aprovadas na $1^{\text {a }}$ CAP, seguida pelo MCidades que incorporou $91 \%$ das sugestões aprovadas na $1^{\text {a }}$ Concidades e do ME que traduziu $89 \%$ das recomendações inéditas da $1^{\text {a }}$ CE na política nacional de esporte:

Tabela 8

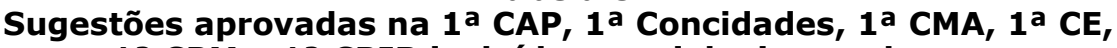
$1^{\text {a }}$ CPM e $1^{\text {a }}$ CPIR incluídas parcial e integralmente nos programas da Seap, MCidades, MMA, ME, SPM e Seppir

\begin{tabular}{|c|c|c|c|c|c|c|c|c|}
\hline \multirow{3}{*}{ Conferência } & \multicolumn{4}{|c|}{$\begin{array}{c}\begin{array}{c}\text { Propostas sugeridas } \\
\text { incluídas }\end{array} \\
\end{array}$} & \multicolumn{4}{|c|}{ Propostas inéditas incluídas } \\
\hline & \multicolumn{2}{|c|}{ Parcialmente } & \multicolumn{2}{|c|}{ Integralmente } & \multicolumn{2}{|c|}{ Parcialmente } & \multicolumn{2}{|c|}{ Integralmente } \\
\hline & $\mathbf{N}$ & $\%$ & $\mathbf{N}$ & $\%$ & $\mathbf{N}$ & $\%$ & $\mathbf{N}$ & $\%$ \\
\hline $1^{\text {a }}$ CAP & 0 & 0,0 & 61 & 100,0 & 0 & 0,0 & 93 & 100,0 \\
\hline $1^{\text {a }}$ Concidades & 7 & 8,0 & 70 & 91,0 & 23 & 22,0 & 82 & 78,0 \\
\hline $1^{\text {a }}$ CMA & 18 & 40,0 & 27 & 60,0 & 33 & 23,0 & 112 & 77,0 \\
\hline $1^{\mathrm{a} C E}$ & 9 & 27,5 & 24 & 72,5 & 2 & 11,0 & 16 & 89,0 \\
\hline $1^{\text {a } C P M}$ & 3 & 20,0 & 12 & 80,0 & 12 & 18,5 & 52 & 81,5 \\
\hline $1^{\text {a }}$ CPIR & 16 & 53,5 & 14 & 46,5 & 85 & 39,5 & 131 & 60,5 \\
\hline Total & 53 & 20,0 & 208 & 80,0 & 155 & 24,0 & 486 & 76,0 \\
\hline
\end{tabular}

Fonte: Formulação própria a partir do Plano de Ação da $1^{\text {a }}$ CAP (Brasil, 2003a, 2004a), da $1^{a}$ Concidades (Brasil, 2003e, 2004b), da $1^{a}$ CMA (Brasil, 2003i, 2003k, 2005a), da 19a CE (Brasil, 2004e, 2005b), da $1^{\text {a }}$ CPM (Brasil, 2004g, 2004i) e da $1^{\text {a }}$ CPIR (Brasil, 2005c, 2009).

Por fim, vale ressaltar que somente as sugestões aprovadas na $1^{\text {a }}$ CPIR foram incorporadas, em maior medida, de forma parcial (Tabela 8). Nas demais cinco 
conferências, a quantidade de sugestões aprovadas e de recomendações inéditas incluídas integralmente pelos ministérios competentes superou a de propostas sugeridas e inéditas parcialmente traduzidas em ações dos respectivos programas de políticas.

Mediante o significativo grau de aprovação nas conferências e de incorporação nos programas das políticas setoriais das propostas sugeridas pela instituição governamental competente às $1^{\text {a } C A P,} 1^{\text {a }}$ Concidades, $1^{\text {a }}$ CMA, $1^{\text {a }}$ CE, $1^{\text {a }}$ CPM e $1^{\text {a }}$ CPIR (Tabelas 5 e 7 respectivamente), tornou-se necessário avaliar a real capacidade de influência dessas conferências sobre as respectivas políticas. Esta corresponde ao efeito relativo das recomendações inéditas em relação ao total de propostas incorporadas. Uma vez que as propostas sugeridas constituem intenções governamentais quanto a determinado assunto e, mesmo quando aprovadas com alterações, mantêm-se como tais, elas não consistem em contribuições do processo conferencial em si e, portanto, não dependem de tal processo para ser incorporadas. Daí a necessidade de isolar o efeito das propostas sugeridas para examinar a capacidade real de influência das conferências, dada pela proporção de recomendações inéditas incorporadas em relação ao total aprovado e incluído. O Gráfico 3 apresenta a capacidade real de influência das seis conferências examinadas:

Gráfico 3

Capacidade real de influência da $1^{\text {a }}$ CAP, $1^{\text {a }}$ Concidades, $1^{\text {a }}$ CMA, $1^{\text {a }}$ CE, $1^{\text {a }}$ CPM e $1^{\text {a }}$ CPIR

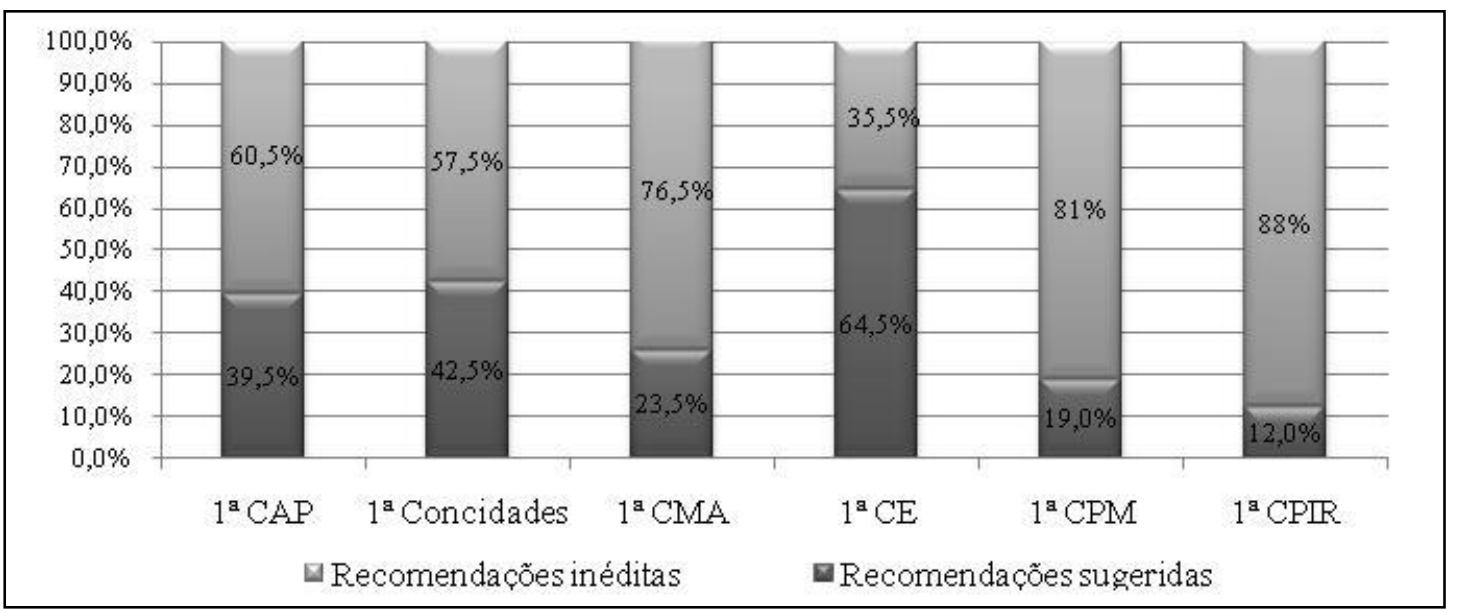

Fonte: Formulação própria a partir dos resultados da Tabela 8. 
Pelo Gráfico 3, observa-se que, de fato, os debates e decisões tomadas na $1^{\text {a }}$ CAP,

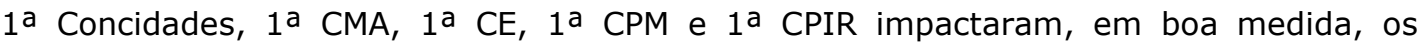
programas de políticas da Seap, do MCidades, do MMA, do ME, da SPM e da Seppir para os anos seguintes aos desses encontros. Metade das conferências - $1^{a}$ CMA, $1^{\text {a }}$ CPM e $1^{a}$ CPIR - alcançou alta capacidade real de influência, uma vez que a quantidade de recomendações inéditas aprovadas nestas e incluídas em programas das respectivas políticas superou $70 \%$ do total aprovado e incorporado. Outra metade - $1^{\text {a }}$ Concidades, $1^{\text {a }}$ CAP e $1^{\text {a }}$ CE - apresentou média capacidade real de influência sobre as respectivas políticas, dado que a porcentagem de recomendações inéditas traduzidas em ações governamentais ficou entre $30 \%$ e $70 \%$. Ademais, salvo para o caso da $1^{\text {a }} \mathrm{CE}$, cuja capacidade real de influência foi $35,5 \%$, as recomendações inéditas das demais conferências examinadas foram traduzidas, em maior medida, em ações da Seap, do MCidades, do MMA, da SPM e da Seppir, comparativamente à quantidade de propostas sugeridas nelas apreciadas e incluídas.

Da $1^{\text {a }}$ Concidades, $1^{\text {a }}$ CAP e $1^{\text {a }} \mathrm{CE}$, resultaram, portanto, políticas de conteúdo partilhado, com ações sugeridas pelos atores governamentais e elaboradas pelos atores societais em conjunto com aqueles nos processos conferenciais (Tabela 9). Já a $1^{\text {a }}$ CMA, a $1^{\text {a }}$ CPM e a $1^{\text {a }}$ CPIR deram origem a políticas com conteúdo predominantemente societário, haja vista que mais de $70 \%$ das propostas aprovadas nesses encontros, incluídas no Plano de Ação do MMA, SPM e Seppir, foram sugeridas, de forma inédita, pelos participantes. A esse respeito, vale destacar a $1^{\text {a }}$ CPIR e a $1^{\text {a }}$ CPM, com $88 \%$ e $81 \%$ de suas recomendações inéditas incorporadas no I Planappir e no I PNPM, respectivamente.

Tabela 9

Conteúdo dos programas da política nacional de aquicultura e pesca, urbana, de meio ambiente, de esporte, de políticas para mulheres e de promoção da igualdade racial, elaborados após a $1^{\text {a }}$ CAP, $1^{\text {a }}$ Concidades, $1^{\text {a }}$ CMA, $1^{\text {a }}$ CE, $1^{\text {a }}$ CPM e $1^{\text {a }}$ CPIR

\begin{tabular}{|c|c|c|c|}
\hline \multirow{2}{*}{ Conferência } & \multicolumn{2}{|c|}{ Capacidade real de influência } & \multirow{2}{*}{$\begin{array}{c}\text { Conteúdo dos } \\
\text { programas de política }\end{array}$} \\
\cline { 2 - 3 } & $\%$ & Grau & Partilhado \\
\hline $1^{\text {a }}$ CAP & 60,5 & Média & Partilhado \\
\hline $1^{\text {a }}$ Concidades & 57,5 & Média & Societário \\
\hline $1^{\text {a }}$ CMA & 76,5 & Alta & Partilhado \\
\hline $1^{\text {a }}$ CE & 35,5 & Média & Societário \\
\hline $1^{\text {a } ~ C P M ~}$ & 81,0 & Alta & Societário \\
\hline $1^{\text {a } C P I R}$ & 88,0 & Alta & \\
\hline
\end{tabular}

Fonte: Formulação própria com base no Gráfico 3. 


\section{Considerações finais}

O processo de políticas públicas no Brasil vem passando por um movimento de democratização nas últimas duas décadas e meia, capitaneado, notadamente, pela criação de instâncias/interfaces participativas integradas a esse processo. Esse conjunto de espaços, mecanismos e/ou instituições vem ampliando a participação social nos momentos de discussão e tomada de decisão no âmbito da administração pública e do Legislativo, promovendo inclusão política (Avritzer, 2013; Cunha, 2013; Pogrebinschi, 2013) e aproximando, de certa forma e em alguma medida, as ações dos representantes eleitos e dos gestores públicos às demandas dos cidadãos (Petinelli, 2011, 2013; Pogrebinschi, 2013; Pogrebinschi e Santos, 2011).

No âmbito nacional, a ampliação da participação social e da influência dos atores societais nas decisões dos atores políticos pode ser atribuída, dentre outros motivos, à realização de conferências em um amplo e variado conjunto de políticas setoriais. Dos debates entre atores estatais e não estatais nessas arenas participativas, milhares de recomendações têm sido produzidas e encaminhadas para as instituições políticas competentes para ser incorporadas às respectivas políticas públicas.

Este artigo buscou propor uma metodologia para aferir os efeitos das recomendações aprovadas nas conferências sobre os programas das respectivas políticas setoriais. O grau de incorporação dessas propostas foi denominado capacidade de influência das conferências e mensurado pela comparação entre o conteúdo das recomendações e o conteúdo dos programas de políticas, elaborados pelas instituições governamentais competentes após as conferências. Esse método foi empregado para aferir a capacidade de influência da $1^{\text {a }}$ conferência de aquicultura e pesca, de cidades, de meio ambiente, de esporte, de políticas para mulheres e de políticas de promoção da igualdade racial.

Dessa investigação, constatou-se que as seis conferências serviram a dois propósitos: como espaços informacionais do Poder Executivo e como processos de proposição de políticas. As discussões e decisões tomadas nesses processos não só sinalizaram, para os atores governamentais, as ações por eles sugeridas que correspondiam, em alguma medida, às demandas dos atores societais participantes destes, como também explicitaram as próprias ideias e preferências desses atores quanto à política debatida.

Nas seis conferências examinadas, a proporção de sugestões governamentais nelas aprovadas e traduzidas em ações pelos ministérios competentes foi expressivamente maior que a de sugestões não aprovadas. Semelhantemente, a proporção de recomendações inéditas aprovadas na $1^{\text {a } C A P}, 1^{\text {a }}$ Concidades, $1^{\text {a }} \mathrm{CMA}, 1^{\text {a }} \mathrm{CE}, 1^{\mathrm{a}} \mathrm{CPM}$ e $1^{\text {a }}$ CPIR, e traduzidas nos programas de políticas da Seap, MCidades, MMA, ME, SPM e Seppir, superou, salvo para a $1^{\text {a }}$ CMA e a $1^{\text {a }}$ CPIR, a proporção de recomendações inéditas não incorporadas. Nesse aspecto, vale chamar atenção para o alto número de 
recomendações inéditas aprovadas nesses dois encontros, o qual foi mais de duas vezes maior que o observado nas demais conferências.

Somado a isso, o total de recomendações inéditas elaboradas foi expressivamente superior ao de sugestões governamentais aprovadas, parcial ou integralmente, em cinco das seis conferências examinadas. Somente na $1^{\mathrm{a}} \mathrm{CE}$, o total de sugestões aprovadas superou o de recomendações inéditas aprovadas. Assim, não obstante a discussão e a apreciação de diretrizes na $1^{\text {a }}$ CAP, $1^{\text {a }}$ Concidades, $1^{\text {a } C M A}, 1^{a} \mathrm{CE}, 1^{\text {a }}$ CPM e $1^{a}$ CPIR terem sido referenciadas por um conjunto de sugestões governamentais, esses processos proporcionaram um rico debate, comprovado, não só pela alta porcentagem de recomendações inéditas aprovadas nestes, mas também pela quantidade expressiva de sugestões incorporadas parcialmente às recomendações.

Esse rico processo de debate e tomada de decisão possibilitou, ademais, que as recomendações inéditas aprovadas em todos os seis encontros impactassem expressivamente as ações governamentais elaboradas nos anos subsequentes ao dessas conferências. A $1^{\text {a }}$ CPIR, a $1^{a}$ CPM e a $1^{\text {a }}$ CMA alcançaram alta capacidade real de influência, uma vez que as recomendações inéditas nelas aprovadas representaram mais de $70 \%$ da capacidade total de influência desses processos sobre as respectivas políticas. Os demais três encontros, $1^{\text {a }}$ Concidades, $1^{\text {a }}$ CAP e $1^{\text {a }} \mathrm{CE}$, obtiveram capacidade média, posto que a quantidade de recomendações inéditas neles aprovada representou entre $31 \%$ e $70 \%$ da capacidade total de influência destas sobre a política urbana, de aquicultura e pesca e de esporte.

Assim, os programas da política de promoção da igualdade racial (I Planappir), das políticas para mulheres (I PNPM) e da política ambiental, construídos a partir da $1^{\text {a }}$ CPIR, $1^{\text {a }}$ CPM e $1^{\text {a }}$ CMA, apresentaram conteúdo predominantemente societário, enquanto os programas da política urbana, de aquicultura e pesca e de esporte combinaram, em proporção mais equilibrada, as ideias dos atores governamentais e da sociedade civil, apresentando conteúdo partilhado, governamental e societário. As seis conferências aqui examinadas, portanto, impactaram, de modo expressivo, o processo de políticas nas quais elas se desenrolaram ao legitimar e/ou deslegitimar as ideias dos atores governamentais nelas apresentadas, dar visibilidade às preferências e propostas dos atores societais e influenciar as decisões tomadas pelos atores governamentais nos momentos seguintes aos encontros.

No entanto, como mostrado, a capacidade de influência dos seis encontros foi diferente. Isso pode estar associado, em alguma medida, a variações em relação ao arcabouço institucional das políticas públicas nelas debatidas - mais ou menos descentralizadas e intersetoriais, mais antigas ou recentes, mais ou menos institucionalizadas -, à dinâmica política entre os participantes - mais ou menos conflituosa, mais ou menos plural, mais ou menos competitiva - , ao perfil dos participantes e ao conteúdo das propostas - contrárias às propostas de setores de governo e de segmentos societais politicamente mais influentes -, dentre outros 
aspectos que impactam, de certa forma, o processo de políticas públicas no qual as conferências estão inseridas. A análise de tais possíveis relações não constitui, porém, objetivo deste artigo, consistindo num potencial objeto de futuras investigações a respeito da capacidade de influência de propostas aprovadas em conferências sobre os programas das respectivas políticas públicas.

Viviane Petinelli - Doutora em Ciência Política. Departamento de Ciência Política. Faculdade de Filosofia e Ciências Humanas. Universidade Federal de Minas Gerais. E-mail: <vpetinelli@hotmail.com>.

\section{Referências bibliográficas}

AVRITZER, L. Conferências Nacionais: ampliando e redefinindo os padrões de participação social no Brasil. In: Avritzer, L.; SouZA, C. H. L. (orgs.). Conferências Nacionais: atores, dinâmicas e efetividade. Brasília: Ipea, 2013.

BRASIL, Seap/PR. Caderno de resoluções da $1^{\text {a }}$ Conferência Nacional de Aquicultura e Pesca. Brasília: Seap/PR, 2003a.

Seap/PR. Programação da $1^{a}$ Conferência Nacional de Aquicultura e Pesca, realizada de 25 a 27 de novembro, em Luziânia, GO. [online]. Brasília: Seap/PR, 2003b. Disponível em: <www.mpa.gov.br>. Acesso em: 22 jul. 2012.

Seap/PR. Portaria Seap, $n^{\circ} 179$, de 28 de agosto de 2003. Aprova o Regimento da Conferência Nacional de Aquicultura e Pesca e dá outras providências [online]. Brasília: Seap/PR, 2003c. Disponível em: <www.mpa.gov.br>. Acesso em: 22 jul. 2012.

. Seap/PR. Projeto Político. Plano Estratégico de Desenvolvimento Sustentável de Aquicultura e Pesca [online]. Brasília: Seap/PR, junho, 2003d. Disponível em: <www.mpa.gov.br>. Acesso em: 22 jul. 2012.

. MCidades. Resoluções da $1^{a}$ Conferência Nacional das Cidades [online]. Brasília:

MCidades, 2003e. Disponível em: <www.cidades.gov.br>. Acesso em: 22 jul. 2012.

. MCidades. Regimento Interno da $1^{a}$ Conferência Nacional das Cidades [online]. Brasília: MCidades, 2003f. Disponível em: <www.cidades.gov.br>. Acesso em: 23 jul. 2012.

. Texto-base da $1^{a}$ Conferência Nacional das Cidades [online]. Brasília: MCidades, 2003g. Disponível em: <www.cidades.gov.br>. Acesso em: 22 jul. 2012.

. MMA. Portaria $n^{\circ} 359$, de 9 de setembro de 2003. Aprova o Regulamento Geral da Conferência Nacional do Meio Ambiente e as normas básicas de sua primeira reunião [online]. Brasília: MMA, 2003h. Disponível em: <www.mma.gov.br>. Acesso em: 22 jul. 2012.

. MMA. Recomendações da $1^{a}$ Conferência Nacional de Meio Ambiente [online]. Brasília: MMA, 2003i. Disponível em <www.mma.gov.br>. Acesso em: 22 jul. 2012.

. MMA. Texto-base da $1^{\text {a }}$ Conferência Nacional de Meio Ambiente [online]. Brasília: MMA, 2003j. Disponível em: <www.mma.gov.br>. Acesso em: 22 jul. 2012. 
BRASIL. Ministério do Planejamento, Orçamento e Gestão - MPOG. Plano Plurianual (2004-2007) [online]. Brasília: MPOG, 2003k. Disponível em http://www.planobrasil.gov.br/. Acesso em: 3 mar. 2013.

Seap/PR. Plano Estratégico de Desenvolvimento Sustentável de Aquicultura e Pesca [online]. Brasília: Seap/PR, 2004a. Disponível em: <www.mpa.gov.br>. Acesso em: 22 jul. 2012.

. MCidades. Cadernos MCidades [online]. Brasília: MCidades, 2004b. Disponível em: <www.capacidades.gov.br>. Acesso em: 3 mar. 2013.

. MCidades. Decreto $n^{\circ} 5.031$, de 2 de abril de 2004. Dispõe sobre a composição, estruturação, competências e funcionamento do Conselho das Cidades, e dá outras providências [online]. Brasília: MCidades, 2004c. Disponível em: <www. planalto.gov.br>. Acesso em: 3 mar. 2013.

. ME. Portaria $n^{\circ} 13$ de 3 de fevereiro de 2004. Aprova o Regulamento Geral da Conferência Nacional do Esporte e as normas básicas de sua primeira reunião [online]. Brasília: ME, 2004d. Disponível em: <www.esporte.gov.br>. Acesso em: 22 mar. 2012.

ME. Conferência Nacional do Esporte. Esporte, Lazer e Desenvolvimento Humano: documento final [online]. Brasília: ME, 2004e. Disponível em: <www.mpa.gov.br>. Acesso em: 3 mar. 2013.

ME. Texto básico sistematizado. $1^{\text {a }}$ Conferência Nacional do Esporte. Esporte, Lazer e Desenvolvimento Humano [online]. Brasília: ME, 2004f. Disponível em: <www.mpa.gov.br>. Acesso em: 3 mar. 2013.

SPM/PR. Anais da $1^{\text {a }}$ Conferência Nacional de Políticas para Mulheres [online]. Brasília: SPM/PR, 2004g. Disponível em: <www.spm.gov.br>. Acesso em: 22 jul. 2012.

. SPM/PR. Contribuição da Secretaria Especial de Políticas para as Mulheres para as Conferências Estaduais [online]. Brasília: SPM/PR, 2004h. Disponível em: <www.spm.gov.br>. Acesso em: 3 mar. 2013.

SPM/PR. Plano Nacional de Políticas para as Mulheres [online]. Brasília: SPM/PR, $2004 \mathrm{i}$. Disponível em: <www.spm.gov.br>. Acesso em: 3 mar. 2013.

. MMA. Vamos cuidar do Brasil. I Conferência Nacional de Meio Ambiente. Ações do MMA para as deliberações da $1^{a}$ CMA [online]. Brasília: MMA, 2005a. Disponível em: <www.mma.gov.br>. Acesso em: 3 mar. 2013.

Ministério do Esporte - ME. Resolução $n^{\circ} 5$ do Conselho Nacional do Esporte, aprovada em 14 de junho de 2005. Aprova a Política Nacional do Esporte [online]. Brasília: ME, 2005b. Disponível em: <www.mpa.gov.br>. Acesso em: 3 mar. 2013.

Seppir/PR. Relatório final da I Conferência Nacional de Políticas de Promoção da Igualdade Racial. Estado e sociedade promovendo igualdade racial [online]. Brasília: Seppir/PR, 2005c. Disponível em: <http://www.portaldaigualdade.gov.br/>. Acesso em: 22 jul. 2012.

Seppir/PR. Texto-base. Estado e sociedade promovendo igualdade racial [online]. Brasília: Seppir/PR, 2005d. Disponível em:

<http://www.presidencia.gov.br/estrutura_presidencia/seppir/publicacoes/>. Acesso em: 3 mar. 2013.

Seppir/ PR. Decreto $n^{\circ}$ 6.872, de 4 de junho de 2009. Aprova o Plano Nacional de Promoção da Igualdade Racial - Planapir, e institui o seu Comitê de Articulação e Monitoramento. 
Brasília: Seppir/ PR, 2009. Disponível em: <http://www.portaldaigualdade.gov.br/portalantigo/planapir/sobre_planapir>. Acesso em: 7 out. 2015.

BRASIL. SGPR. Lista de conselhos e de conferências nacionais. Brasília: SGPR, 2013a. Disponível em: <www.secretariageral.gov.br>. Acesso em: 3 mar. 2013.

. MPA, 2013b. Disponível em: <www.mpa.gov.br>. Acesso em: 3 mar. 2013.

. MCidades, 2013c. Disponível em: <www.cidades.gov.br>. Acesso em: 3 mar. 2013.

. ME, 2013d. Disponível em: <www.esporte.gov.br>. Acesso em: 3 mar. 2013.

SPM, 2013e. Disponível em: <www.spm.gov.br>. Acesso em: 3 mar. 2013.

. Seppir, 2013f. Disponível em: <www.seppir.gov.br>. Acesso em: 3 mar. 2013.

CUNHA, E. S. M. Conferências de políticas públicas e inclusão participativa. In: AVRITZER, L.; SouZA, C. H. L. (orgs.). Conferências Nacionais: atores, dinâmicas e efetividade. Brasília: Ipea, 2013.

PetinelLi, V. "As conferências públicas nacionais e a formação da agenda de políticas públicas do governo federal (2003-2010)". Opinião Pública, Campinas, vol. 17, n 1, p. 228-250, jun. 2011.

Contexto político, natureza da política, organização da sociedade civil e desenho institucional: alguns condicionantes da efetividade das conferências nacionais. Rio de Janeiro: Ipea, 2013.

"Uma análise dos condicionantes da capacidade de influência das conferências de políticas públicas sobre os programas das respectivas políticas setoriais: o caso da $1^{\text {a }}$ CAP, $1^{a}$ Concidades, $1^{\text {a } C M A}, 1^{a} \mathrm{CE}, 1^{\text {a }}$ CPM e $1^{\text {a }}$ CPIR". Tese de Doutorado em Ciência Política. Faculdade de Filosofia e Ciências Humanas, Universidade Federal de Minas Gerais, Belo Horizonte, 2014.

PIRES, R. R. (org.). Efetividade das instituições participativas no Brasil: estratégias de avaliação. Brasília: Ipea, 2011.

PogreBINSCHI, T. Conferências nacionais e políticas públicas para grupos minoritários. In: AVRITZER, L.; SouzA, C. H. L. (orgs.). Conferências Nacionais: atores, dinâmicas e efetividade. Brasília: Ipea, 2013.

PogReBINSCHI, T.; SANTOS, F. "Participação como representação: o impacto das conferências nacionais de políticas públicas no Congresso Nacional". Dados - Revista de Ciências Sociais, vol. 54, $n^{\circ} 3,2011$.

SouzA, C. H. L. "A que vieram as conferências nacionais? Uma análise dos objetivos dos processos realizados entre 2003 e 2010". Texto para discussão Ipea 1718. Rio de Janeiro: Ipea, 2012. 


\section{Resumo}

Aferindo a capacidade de influência das conferências de políticas públicas sobre os programas das respectivas políticas setoriais

Este artigo propõe um método para aferir a capacidade de influência de conferências de políticas públicas sobre as respectivas políticas. Por capacidade de influência, entende-se o grau de incorporação das propostas aprovadas nessas arenas participativas nos programas das políticas setoriais. Posto que as propostas aprovadas consistem tanto de sugestões do ministério organizador como de diretrizes inéditas elaboradas na conferência, este artigo avalia o grau de incorporação dessas propostas separadamente e denomina capacidade real de influência a proporção relativa de recomendações inéditas incorporadas em relação ao total. Esta análise é empregada para a $1^{a}$ Conferência de Aquicultura e Pesca, de Cidades, de Meio Ambiente, de Esporte, de Políticas para Mulheres e de Promoção da Igualdade Racial. Constata-se que as conferências têm servido enquanto espaços informacionais e propositores de novas políticas.

Palavras-chaves: conferências de políticas públicas; programas de políticas governamentais; governo

\section{Abstract \\ Assessing the degree of influence of policy conferences on their respective policies}

This article proposes a method to measure the capacity of policy conferences to influence the making of policies, by incorporating the proposal approved in the participatory forums. Once the approved proposals are both suggestions of the organizing department and new guidelines emerged from the conference process, this article assesses the degree of incorporation of both kinds of proposals separately and names the real influence of the policy conferences as the proportion of new proposals incorporated over the total. This analysis is employed for the $1^{\text {st }}$ Conference of Aquaculture and Fisheries, Urban Policies, Environment, Sports, Women's Policies and Policies to Promote Racial Equality and shows the conferences have served as informational forums of new policies.

Keywords: policy conferences; policies; government

\section{Resumen}

Midiendo la capacidad de influir de las conferencias de políticas públicas en los respectivos programas de políticas sectoriales

Este trabajo propone un método para evaluar la capacidad de influir de las conferencias de políticas públicas en sus respectivas políticas sectoriales. La capacidad de influir se define como el grado de incorporación de las propuestas aprobadas en estas arenas participativas, en los programas de sus respectivas políticas sectoriales. Dado que las propuestas aprobadas consisten tanto en sugerencias del ministerio organizador de la conferencia como en directrices inéditas desarrolladas en dicha conferencia, este artículo evalúa el grado de incorporación de estas propuestas por separado y llama capacidad real de influir la proporción relativa de las recomendaciones publicadas, incorporadas en el total. Este análisis se emplea para la primera Conferencia de Acuacultura y Pesca, de Ciudades, de Medio Ambiente, de Deportes, de Políticas para la Mujer y de Promoción de la Igualdad Racial. El trabajo muestra que las conferencias han servido como espacios de información y para la proposición de nuevas políticas.

Palabras-claves: conferencias de políticas públicas; programas de políticas gubernamentales; gobierno 


\section{Résumé}

La mesure de l'influence des conférences de politiques publiques sur les programmes de leurs respectives politiques sectorielles

Cet article propose une méthode pour évaluer I'influence des conférences de politiques publiques sur leurs respectives politiques sectorielles. La capacité d'influencer est définie comme le degré d'incorporation des propositions, approuvées dans ces arènes participatives, dans les programmes de politiques sectorielles. Comme les propositions approuvées se composent de suggestions du ministère organisateur ainsi que de directives inédites développées lors de la conférence, cet article évalue le degré d'intégration de ces propositions séparément et il nomme capacité réelle d'influencer, la proportion relative de recommandations inédites incorporées par rapport au nombre au total de propositions. Cette analyse est utilisée pour la 1ère Conférence de I'Aquaculture et de la Pêche, des Villes, de I'Environnement, du Sport, de Politiques de la Femme et de Promotion de I'Égalité raciale. On constate que les conférences ont servi d'espaces d'information et de promotion de nouvelles politiques.

Mots-clés: conférences de politiques publiques; programmes de politiques gouvernementales ; gouvernement

Artigo submetido à publicação em junho de 2014. Versão final aprovada em agosto de 2015. 